\title{
Gene Genealogies Reveal High Nucleotide Diversity and Admixture Haplotypes Within Three Alternaria Species Associated with Tomato and Potato
}

\author{
Tika B. Adhikari, ${ }^{1, \dagger}$ Thomas Ingram, ${ }^{1}$ Dennis Halterman, ${ }^{2}$ and Frank J. Louws ${ }^{1,3, \dagger}$ \\ ${ }^{1}$ Department of Entomology and Plant Pathology, North Carolina State University, Raleigh, NC 27695 \\ ${ }^{2}$ United States Department of Agriculture-Agricultural Research Service, Vegetable Crops Research Unit, Madison, WI 53706 \\ ${ }^{3}$ Department of Horticultural Science, North Carolina State University, Raleigh, NC 27695 \\ Accepted for publication 22 March 2020.
}

ABSTRACT

\begin{abstract}
Early blight (EB) and leaf blight are two destructive diseases of tomato in North Carolina (NC), caused by Alternaria linariae and A. alternata, respectively. During the last decade, EB caused by A. solani has increased in potato-producing areas in Wisconsin (WI). We collected 152 isolates of three Alternaria spp. associated with tomato and potato in NC and WI and used the gene genealogical approach to compare the genetic relationships among them. Two nuclear genes: the glyceraldehyde-3-phosphate dehydrogenase $(G P D H)$, RNA polymerase second largest subunit (RPB2), and the rDNA internal transcribed spacer (ITS) region of these isolates were sequenced. Besides, sequences of the GPDH locus from international isolates described in previous studies were included for comparison purposes. A set of single nucleotide polymorphisms was assembled to identify locus-specific and species-specific haplotypes. Nucleotide diversity varied among gene sequences and species analyzed. For example, the estimates of nucleotide diversity and Watterson's theta were higher in A. alternata than in A. linariae and A. solani. There was little or no
\end{abstract}

polymorphisms in the ITS sequences and thus restricted haplotype placement. The $R P B 2$ sequences were less informative to detect haplotype diversity in A. linariae and A. solani, yet six haplotypes were detected in $A$. alternata. The GPDH sequences enabled strongly supported phylogenetic inferences with the highest haplotype diversity and belonged to five haplotypes (AaH1 to AaH5), which consisted of only A. alternata from NC. However, 13 haplotypes were identified within and among A. linariae and A. solani sequences. Among them, six (AsAlH1 to AsAlH6) were identical to previously reported haplotypes in global samples and the remaining were new haplotypes. The most divergent haplotypes were AaH1, AsAlH2/ AsAlH3, and AsAlH4 and consisted exclusively of A. alternata, A. linariae, and A. solani, respectively. Neutrality tests suggested an excess of mutations and population expansion, and selection may play an important role in nucleotide diversity of Alternaria spp.

Keywords: mycology, population biology
Tomato (Solanum lycopersicum L.) and potato (Solanum tuberosum L.) represent important vegetables in North Carolina (NC) and Wisconsin (WI), respectively. Most of the tomato production is in western $\mathrm{NC}$ and sporadic in eastern NC and the Piedmont region. On the other hand, potato is a major vegetable in WI, which is the third largest potato-producing state in the country (USDA-NASS 2018). Commercial potato cultivars grown in WI are Russet, White, Red, Yellow, Blue, and Fingerling. Different Alternaria species (spp.) were found to be associated with early blight (EB) of tomato and potato (Rotem 1994; Simmons 2000). Based on morphology, Alternaria specimens from Solanaceae were revised into several new species including A. grandis (Simmons 2000, 2007). Besides $A$. solani sensu stricto (Ell. and Mart.) Jones and Grout and A. grandis from potato, a new species called A. tomatophila was identified to cause EB on tomato (Simmons 2007). Later, this species was named A. linariae (Neerg.) Simmons infecting Solanaceae, Cucurbitaceae, and Scrophulariaceae (Woudenberg et al. 2014). A. alternata sensu lato (Fr.) Keissler has been repeatedly isolated from Solanaceae with symptoms resembling that of EB. Although A. alternata causes brown leaf spot on potato (Ding et al. 2019; Droby et al. 1984) and leaf blight and stem canker on tomato (Grogan et al. 1975), both

${ }^{\dagger}$ Corresponding authors: T. B. Adhikari; tbadhika@ncsu.edu, and

F. J. Louws; fjlouws@ncsu.edu

*The $e$-Xtra logo stands for "electronic extra" and indicates that supplementary tables are published online.

The author(s) declare no conflict of interest.

(c) 2020 The American Phytopathological Society diseases pose a serious challenge for tomato and potato growers due to the lack of effective resistant cultivars (Adhikari et al. 2017).

DNA sequencing approaches have provided data for both gene genealogies and phylogenetic analyses of genetic variations in different fungi (Brewer and Milgroom 2010; O'Donnell et al. 2000; Peever et al. 2002; Zaffarano et al. 2009). Gene genealogies have provided the evolutionary history and genetic relationships among and within populations in some fungi (Brewer and Milgroom 2010; O'Donnell et al. 2000; Zaffarano et al. 2009) including A. alternata from citrus (Peever et al. 2002). Multigene phylogenies using ribosomal DNA and the nuclear genes such as glyceraldehyde-3phosphate dehydrogenase $(G P D H)$, internal transcribed spacer (ITS), translation elongation factor $1(E F-1 \alpha)$, and the gene encoding the allergenic protein alt a 1 (Alt a 1 ) have been used to determine phylogenetic relationships among isolates of $A$. solani and A. alternata from tomato and potato from Brazil and WI (Ding et al. 2019; Lourenço et al. 2009). Leaf blight and EB, caused by $A$. alternata and A. linariae (syn. A. tomatophila), respectively, are destructive diseases of tomato in the United States (Jones et al. 2014). A. linariae is considered a primary pathogen causing EB on tomato (Woudenberg et al. 2014), but it can also infect potato (Ayad et al. 2017). Similarly, EB is a major disease of potato and is spread worldwide including in the United States (Pryor and Gilbertson 2000).

Tomato is an important vegetable and widely cultivated in western NC. A. linariae is a serious threat to tomato production, resulting in severe economic losses in the Southeastern United States including NC (Kuhar et al. 2019). Unlike A. linariae, A. alternata on tomato has been a neglected pathogen and is poorly understood in NC. Although these pathogens were common in $\mathrm{NC}$, the currently available knowledge on molecular diversity of 
TABLE 1. Identity, host plant, geographic location of origin, accession number, and isolates of Alternaria species used in this study

\begin{tabular}{|c|c|c|c|c|c|c|c|c|c|}
\hline Serial number & Species & Isolate $^{b}$ & Haplotype ${ }^{c}$ & Host plant of origin & Country of origin & County & State & Year & Accession number \\
\hline 1 & A. alternata & GA4 & $\mathrm{AaH} 1$ & Asian ginseng & China & & & 2019 & MK451978 \\
\hline 2 & & GSJP6 & $\mathrm{AaH} 1$ & Asian ginseng & China & & & 2019 & MK451976 \\
\hline 3 & & GR1 & $\mathrm{AaH} 1$ & Asian ginseng & China & & & 2019 & MK451975 \\
\hline 4 & & MRY1 & $\mathrm{AaH} 1$ & Ashitaba & China & & & 2019 & MK210169 \\
\hline 5 & & MFLUCC:18-1586 & $\mathrm{AaH} 1$ & Cherry & China & & & 2018 & MH853658 \\
\hline 6 & & JZB380002 & $\mathrm{AaH} 1$ & Cherry & China & & & 2018 & MH853645 \\
\hline 7 & & HMCH-9 & $\mathrm{AaH} 1$ & Italian ryegrass & China & & & 2018 & MH567107 \\
\hline 8 & & A01 & $\mathrm{AaH} 1$ & Chinese rose & China & & & 2018 & MH248152 \\
\hline 9 & & YMAa1/IRAN2643C & $\mathrm{AaH} 1$ & Sea squill & Iran & & & 2016 & KY231161 \\
\hline 10 & & CCTU 211 & $\mathrm{AaH} 1$ & Common sunflower & Iran & & & 2013 & KC835770 \\
\hline 11 & & CCTU 212 & $\mathrm{AaH} 1$ & Common sunflower & Iran & & & 2014 & KC835771 \\
\hline 12 & & AE1 & $\mathrm{AaH} 1$ & Cast iron & Italy & & & 2017 & KY676195 \\
\hline 13 & & 211 & $\mathrm{AaH} 1$ & Peace lily & Serbia & & & 2015 & KP851761 \\
\hline 14 & & 181 & $\mathrm{AaH} 1$ & Peace lily & Serbia & & & 2016 & KP851756 \\
\hline 15 & & $986 / 2$ & $\mathrm{AaH} 1$ & Horseradish & Serbia & & & 2017 & MF741818 \\
\hline 16 & & RG3 & $\mathrm{AaH} 1$ & Radish & South Korea & & & 2017 & MG250620 \\
\hline 17 & & RGW8 & $\mathrm{AaH} 1$ & Radish & South Korea & & & 2018 & MG250622 \\
\hline 18 & & MUTITA:856 & $\mathrm{AaH} 1$ & Sea cucumber & Tunisia & & & 2018 & MG832208 \\
\hline 19 & & $\mathrm{~T}-5$ & $\mathrm{AaH} 1$ & Tomato & U.S.A. & Henderson & $\mathrm{NC}$ & 2012 & MK928664 \\
\hline 20 & & $\mathrm{~T}-49$ & $\mathrm{AaH} 5$ & Tomato & U.S.A. & Henderson & $\mathrm{NC}$ & 2012 & MK928686 \\
\hline 21 & & $\mathrm{~T}-51$ & $\mathrm{AaH} 5$ & Tomato & U.S.A. & Henderson & $\mathrm{NC}$ & 2012 & MK928687 \\
\hline 22 & & $\mathrm{~T}-52$ & $\mathrm{AaH} 1$ & Tomato & U.S.A. & Henderson & $\mathrm{NC}$ & 2012 & MK928688 \\
\hline 23 & & $\mathrm{~T}-53$ & $\mathrm{AaH} 1$ & Tomato & U.S.A. & Henderson & $\mathrm{NC}$ & 2012 & MK928689 \\
\hline 24 & & $\mathrm{~T}-54$ & $\mathrm{AaH} 1$ & Tomato & U.S.A. & Henderson & $\mathrm{NC}$ & 2012 & MK928690 \\
\hline 25 & & $\mathrm{~T}-16$ & $\mathrm{AaH} 2$ & Tomato & U.S.A. & Pender & $\mathrm{NC}$ & 2012 & MK928670 \\
\hline 26 & & $\mathrm{~T}-36$ & $\mathrm{AaH} 3$ & Tomato & U.S.A. & Pender & $\mathrm{NC}$ & 2012 & MK928678 \\
\hline 27 & & T-66 & $\mathrm{AaH} 1$ & Tomato & U.S.A. & Pender & $\mathrm{NC}$ & 2012 & MK928699 \\
\hline 28 & & $\mathrm{~T}-8$ & $\mathrm{AaH} 1$ & Tomato & U.S.A. & Sampson & $\mathrm{NC}$ & 2012 & MK928666 \\
\hline 29 & & $\mathrm{~T}-9$ & $\mathrm{AaH} 1$ & Tomato & U.S.A. & Sampson & $\mathrm{NC}$ & 2012 & MK928667 \\
\hline 30 & & T-56 & $\mathrm{AaH} 1$ & Tomato & U.S.A. & Sampson & $\mathrm{NC}$ & 2012 & MK928691 \\
\hline 31 & & $\mathrm{~T}-57$ & $\mathrm{AaH} 1$ & Tomato & U.S.A. & Sampson & $\mathrm{NC}$ & 2012 & MK928692 \\
\hline 32 & & $\mathrm{~T}-7$ & $\mathrm{AaH} 1$ & Tomato & U.S.A. & Stokes & $\mathrm{NC}$ & 2012 & MK928665 \\
\hline 33 & & $\mathrm{~T}-11$ & $\mathrm{AaH} 1$ & Tomato & U.S.A. & Stokes & $\mathrm{NC}$ & 2012 & MK928668 \\
\hline 34 & & $\mathrm{~T}-12$ & $\mathrm{AaH} 1$ & Tomato & U.S.A. & Stokes & $\mathrm{NC}$ & 2012 & MK928669 \\
\hline 35 & & $\mathrm{~T}-17$ & $\mathrm{AaH} 1$ & Tomato & U.S.A. & Stokes & $\mathrm{NC}$ & 2012 & MK928671 \\
\hline 36 & & T-18 & $\mathrm{AaH} 1$ & Tomato & U.S.A. & Stokes & $\mathrm{NC}$ & 2012 & MK928672 \\
\hline 37 & & $\mathrm{~T}-23$ & $\mathrm{AaH} 1$ & Tomato & U.S.A. & Stokes & $\mathrm{NC}$ & 2012 & MK928673 \\
\hline 38 & & T-28 & $\mathrm{AaH} 1$ & Tomato & U.S.A. & Stokes & $\mathrm{NC}$ & 2012 & MK928674 \\
\hline 39 & & $\mathrm{~T}-30$ & $\mathrm{AaH} 1$ & Tomato & U.S.A. & Stokes & $\mathrm{NC}$ & 2012 & MK928675 \\
\hline 40 & & $\mathrm{~T}-32$ & $\mathrm{AaH} 1$ & Tomato & U.S.A. & Stokes & $\mathrm{NC}$ & 2012 & MK928676 \\
\hline 41 & & $\mathrm{~T}-35$ & $\mathrm{AaH} 1$ & Tomato & U.S.A. & Stokes & $\mathrm{NC}$ & 2012 & MK928677 \\
\hline 42 & & $\mathrm{~T}-37$ & $\mathrm{AaH} 1$ & Tomato & U.S.A. & Stokes & $\mathrm{NC}$ & 2012 & MK928679 \\
\hline 43 & & $\mathrm{~T}-38$ & $\mathrm{AaH} 1$ & Tomato & U.S.A. & Stokes & $\mathrm{NC}$ & 2012 & MK928680 \\
\hline 44 & & T-39 & $\mathrm{AaH} 4$ & Tomato & U.S.A. & Stokes & $\mathrm{NC}$ & 2012 & MK928681 \\
\hline 45 & & $\mathrm{~T}-40$ & $\mathrm{AaH} 5$ & Tomato & U.S.A. & Stokes & $\mathrm{NC}$ & 2012 & MK928682 \\
\hline 46 & & $\mathrm{~T}-41$ & $\mathrm{AaH} 1$ & Tomato & U.S.A. & Stokes & $\mathrm{NC}$ & 2012 & MK928683 \\
\hline 47 & & $\mathrm{~T}-43$ & $\mathrm{AaH} 1$ & Tomato & U.S.A. & Stokes & $\mathrm{NC}$ & 2012 & MK928684 \\
\hline 48 & & T-46 & $\mathrm{AaH} 1$ & Tomato & U.S.A. & Stokes & $\mathrm{NC}$ & 2012 & MK928685 \\
\hline 49 & & T-59 & $\mathrm{AaH} 9$ & Tomato & U.S.A. & Stokes & $\mathrm{NC}$ & 2012 & MK928693 \\
\hline 50 & & T-60 & $\mathrm{AaH} 5$ & Tomato & U.S.A. & Stokes & $\mathrm{NC}$ & 2012 & MK928694 \\
\hline 51 & & T-61 & $\mathrm{AaH} 1$ & Tomato & U.S.A. & Stokes & $\mathrm{NC}$ & 2012 & MK928695 \\
\hline 52 & & T-62 & $\mathrm{AaH} 1$ & Tomato & U.S.A. & Stokes & $\mathrm{NC}$ & 2012 & MK928696 \\
\hline 53 & & T-63 & $\mathrm{AaH} 1$ & Tomato & U.S.A. & Stokes & $\mathrm{NC}$ & 2012 & MK928697 \\
\hline 54 & & T-65 & $\mathrm{AaH} 1$ & Tomato & U.S.A. & Stokes & $\mathrm{NC}$ & 2012 & MK928698 \\
\hline 55 & & T-67 & $\mathrm{AaH} 1$ & Tomato & U.S.A. & Stokes & $\mathrm{NC}$ & 2014 & MK928700 \\
\hline 56 & & T-68 & $\mathrm{AaH} 1$ & Tomato & U.S.A. & Stokes & $\mathrm{NC}$ & 2014 & MK928701 \\
\hline 57 & & T-69 & $\mathrm{AaH} 1$ & Tomato & U.S.A. & Stokes & $\mathrm{NC}$ & 2014 & MK928702 \\
\hline 58 & & $\mathrm{~T}-71$ & $\mathrm{AaH} 3$ & Tomato & U.S.A. & Stokes & $\mathrm{NC}$ & 2014 & MK928703 \\
\hline 59 & & $\mathrm{~T}-72$ & $\mathrm{AaH} 1$ & Tomato & U.S.A. & Stokes & $\mathrm{NC}$ & 2014 & MK928704 \\
\hline 60 & & $\mathrm{~T}-73$ & $\mathrm{AaH} 1$ & Tomato & U.S.A. & Stokes & $\mathrm{NC}$ & 2014 & MK928705 \\
\hline 61 & & $\mathrm{~T}-74$ & $\mathrm{AaH} 1$ & Tomato & U.S.A. & Stokes & $\mathrm{NC}$ & 2014 & MK928706 \\
\hline 62 & & $\mathrm{~T}-76$ & $\mathrm{AaH} 1$ & Tomato & U.S.A. & Stokes & $\mathrm{NC}$ & 2014 & MK928707 \\
\hline 63 & & $\mathrm{~T}-77$ & $\mathrm{AaH} 3$ & Tomato & U.S.A. & Stokes & $\mathrm{NC}$ & 2014 & MK928708 \\
\hline 64 & & $\mathrm{~T}-79$ & $\mathrm{AaH} 10$ & Tomato & U.S.A. & Stokes & $\mathrm{NC}$ & 2014 & MK928709 \\
\hline 65 & & SAa1 & $\mathrm{AaH} 1$ & Potato & U.S.A. & & WI & 2019 & MG525459 \\
\hline 66 & & $\mathrm{SAa} 2$ & $\mathrm{AaH} 1$ & Potato & U.S.A. & & WI & 2019 & MG525460 \\
\hline & & & & & & & & \multicolumn{2}{|c|}{ (Continued on next page) } \\
\hline
\end{tabular}

a The sequences of the global isolates of Alternaria spp. were included for comparison purposes.

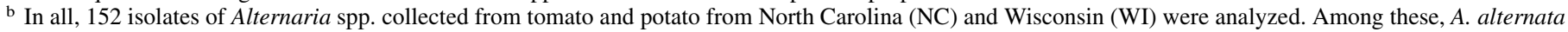
isolates $(N=46)$ were collected from heirloom tomatoes and hybrids in the northeast and central NC. A. linariae $(N=59)$ were collected from commercial hybrid tomatoes in the western NC. A. solani isolates $(N=47)$ were collected from potato cultivars and lines in Waushara County, WI. Sequences of the glyceraldehyde3-phosphate dehydrogenase $(G P D H)$ gene of the isolates from different countries were downloaded (https://www.ncbi.nlm.nih.gov/genbank/) for comparison purposes.


those described previously (Lourenço et al. 2009), and - indicates isolate sequenced but not assigned to a designated haplotype. 
TABLE 1. (Continued from previous page)

\begin{tabular}{|c|c|c|c|c|c|c|c|c|c|}
\hline Serial number & Species & Isolate $^{\mathrm{b}}$ & Haplotype $^{\mathrm{c}}$ & Host plant of origin & Country of origin & County & State & Year & Accession number \\
\hline 67 & & SAa3 & $\mathrm{AaH} 1$ & Potato & U.S.A. & & WI & 2019 & MG525461 \\
\hline 68 & & SAa4 & $\mathrm{AaH} 1$ & Potato & U.S.A. & & WI & 2019 & MG525462 \\
\hline 69 & & SAa5 & $\mathrm{AaH} 1$ & Potato & U.S.A. & & WI & 2019 & MG525463 \\
\hline 70 & & SAa6 & $\mathrm{AaH} 1$ & Potato & U.S.A. & & WI & 2019 & MG525464 \\
\hline 71 & & SAa7 & $\mathrm{AaH} 1$ & Potato & U.S.A. & & WI & 2019 & MG525465 \\
\hline 72 & & SAa8 & $\mathrm{AaH} 1$ & Potato & U.S.A. & & WI & 2019 & MG525466 \\
\hline 73 & & SAa9 & $\mathrm{AaH} 1$ & Potato & U.S.A. & & WI & 2019 & MG525467 \\
\hline 74 & & SAa10 & $\mathrm{AaH} 1$ & Potato & U.S.A. & & WI & 2019 & MG525468 \\
\hline 75 & & Aa35 & $\mathrm{AaH} 1$ & Potato & U.S.A. & & WI & 2019 & MF279611 \\
\hline 76 & & Aa79 & $\mathrm{AaH} 1$ & Potato & U.S.A. & & WI & 2019 & MF279640 \\
\hline 77 & & Aa60 & $\mathrm{AaH} 1$ & Potato & U.S.A. & & WI & 2019 & MF279624 \\
\hline 78 & & Aa52 & $\mathrm{AaH} 2$ & Potato & U.S.A. & & WI & 2019 & MF279619 \\
\hline 79 & & $\mathrm{Aa} 70$ & $\mathrm{AaH} 2$ & Potato & U.S.A. & & WI & 2019 & MF279631 \\
\hline 80 & A. linariae & NB264 & - & Tomato & Algeria & & & 2016 & KR911760 \\
\hline 81 & & NB242 & AsAlH2/H3 & Tomato & Algeria & & & 2016 & KR911762 \\
\hline 82 & & NB272 & AsAlH4 & Tomato & Algeria & & & 2016 & KR911758 \\
\hline 83 & & NB248 & AsAlH1 & Tomato & Algeria & & & 2016 & KR911748 \\
\hline 84 & & 1 & - & Tomato & U.S.A. & Haywood & $\mathrm{NC}$ & 2014 & MK928757 \\
\hline 85 & & 2 & AsAlH2/H3 & Tomato & U.S.A. & Haywood & $\mathrm{NC}$ & 2014 & MK928758 \\
\hline 86 & & 4 & AsAlH9 & Tomato & U.S.A. & Haywood & $\mathrm{NC}$ & 2014 & MK928759 \\
\hline 87 & & 7 & AsAlH2/H3 & Tomato & U.S.A. & Haywood & $\mathrm{NC}$ & 2014 & MK928760 \\
\hline 88 & & 8 & AsAlH2/H3 & Tomato & U.S.A. & Haywood & $\mathrm{NC}$ & 2014 & MK928761 \\
\hline 89 & & 9 & AsAlH2/H3 & Tomato & U.S.A. & Haywood & $\mathrm{NC}$ & 2014 & MK928762 \\
\hline 90 & & 10 & AsAlH2/H3 & Tomato & U.S.A. & Haywood & $\mathrm{NC}$ & 2014 & MK928763 \\
\hline 91 & & 14 & AsAlH2/H3 & Tomato & U.S.A. & Haywood & $\mathrm{NC}$ & 2014 & MK928764 \\
\hline 92 & & 17 & AsAlH7 & Tomato & U.S.A. & Haywood & $\mathrm{NC}$ & 2014 & MK928765 \\
\hline 93 & & 111 & AsAlH11 & Tomato & U.S.A. & Haywood & $\mathrm{NC}$ & 2014 & MK928811 \\
\hline 94 & & 113 & AsAlH11 & Tomato & U.S.A. & Haywood & $\mathrm{NC}$ & 2014 & MK928812 \\
\hline 95 & & 114 & AsAlH11 & Tomato & U.S.A. & Haywood & $\mathrm{NC}$ & 2014 & MK928813 \\
\hline 96 & & 115 & AsAlH2/H3 & Tomato & U.S.A. & Haywood & $\mathrm{NC}$ & 2014 & MK928814 \\
\hline 97 & & 19 & - & Tomato & U.S.A. & Swain & $\mathrm{NC}$ & 2014 & MK928766 \\
\hline 98 & & 20 & AsAlH7 & Tomato & U.S.A. & Swain & $\mathrm{NC}$ & 2014 & MK928767 \\
\hline 99 & & 22 & AsAlH7 & Tomato & U.S.A. & Swain & $\mathrm{NC}$ & 2014 & MK928768 \\
\hline 100 & & 23 & AsAlH7 & Tomato & U.S.A. & Swain & $\mathrm{NC}$ & 2014 & MK928769 \\
\hline 101 & & 30 & AsAlH7 & Tomato & U.S.A. & Swain & $\mathrm{NC}$ & 2014 & MK928770 \\
\hline 102 & & 33 & AsAlH8 & Tomato & U.S.A. & Swain & $\mathrm{NC}$ & 2014 & MK928771 \\
\hline 103 & & 34 & AsAlH7 & Tomato & U.S.A. & Swain & $\mathrm{NC}$ & 2014 & MK928772 \\
\hline 104 & & 36 & AsAlH7 & Tomato & U.S.A. & Swain & $\mathrm{NC}$ & 2014 & MK928773 \\
\hline 105 & & 37 & AsAlH8 & Tomato & U.S.A. & Swain & $\mathrm{NC}$ & 2014 & MK928774 \\
\hline 106 & & 40 & AsAlH7 & Tomato & U.S.A. & Swain & $\mathrm{NC}$ & 2014 & MK928775 \\
\hline 107 & & 41 & AsAlH7 & Tomato & U.S.A. & Swain & $\mathrm{NC}$ & 2014 & MK928776 \\
\hline 108 & & 45 & AsAlH2/H3 & Tomato & U.S.A. & Macon & $\mathrm{NC}$ & 2014 & MK928777 \\
\hline 109 & & 46 & AsAlH2/H3 & Tomato & U.S.A. & Macon & $\mathrm{NC}$ & 2014 & MK928778 \\
\hline 110 & & 47 & AsAlH2/H3 & Tomato & U.S.A. & Macon & $\mathrm{NC}$ & 2014 & MK928779 \\
\hline 111 & & 48 & AsAlH10 & Tomato & U.S.A. & Macon & $\mathrm{NC}$ & 2014 & MK928780 \\
\hline 112 & & 49 & AsAlH2/H3 & Tomato & U.S.A. & Macon & $\mathrm{NC}$ & 2014 & MK928781 \\
\hline 113 & & 50 & AsAlH2/H3 & Tomato & U.S.A. & Macon & $\mathrm{NC}$ & 2014 & MK928782 \\
\hline 114 & & 51 & AsAlH1 & Tomato & U.S.A. & Macon & $\mathrm{NC}$ & 2014 & MK928783 \\
\hline 115 & & 52 & AsAlH2/H3 & Tomato & U.S.A. & Macon & $\mathrm{NC}$ & 2014 & MK928784 \\
\hline 116 & & 54 & AsAlH10 & Tomato & U.S.A. & Macon & $\mathrm{NC}$ & 2014 & MK928785 \\
\hline 117 & & 55 & AsAlH11 & Tomato & U.S.A. & Macon & $\mathrm{NC}$ & 2014 & MK928786 \\
\hline 118 & & 56 & AsAlH9 & Tomato & U.S.A. & Macon & $\mathrm{NC}$ & 2014 & MK928787 \\
\hline 119 & & 57 & AsAlH2/H3 & Tomato & U.S.A. & Macon & $\mathrm{NC}$ & 2014 & MK928788 \\
\hline 120 & & 59 & - & Tomato & U.S.A. & Macon & $\mathrm{NC}$ & 2014 & MK928789 \\
\hline 121 & & 60 & AsAlH9 & Tomato & U.S.A. & Macon & $\mathrm{NC}$ & 2014 & MK928790 \\
\hline 122 & & 62 & AsAlH10 & Tomato & U.S.A. & Macon & $\mathrm{NC}$ & 2014 & MK928791 \\
\hline 123 & & 64 & - & Tomato & U.S.A. & Macon & $\mathrm{NC}$ & 2014 & MK928792 \\
\hline 124 & & 65 & AsAlH10 & Tomato & U.S.A. & Macon & $\mathrm{NC}$ & 2014 & MK928793 \\
\hline 125 & & 67 & AsAlH2/H3 & Tomato & U.S.A. & Macon & $\mathrm{NC}$ & 2014 & MK928794 \\
\hline 126 & & 73 & AsAlH10 & Tomato & U.S.A. & Macon & $\mathrm{NC}$ & 2014 & MK928795 \\
\hline 127 & & 75 & AsAlH10 & Tomato & U.S.A. & Macon & $\mathrm{NC}$ & 2014 & MK928796 \\
\hline 128 & & 81 & AsAlH10 & Tomato & U.S.A. & Madison & $\mathrm{NC}$ & 2014 & MK928797 \\
\hline 129 & & 83 & AsAlH8 & Tomato & U.S.A. & Madison & $\mathrm{NC}$ & 2014 & MK928798 \\
\hline 130 & & 84 & AsAlH2/H3 & Tomato & U.S.A. & Madison & $\mathrm{NC}$ & 2014 & MK928799 \\
\hline 131 & & 85 & AsAlH2/H3 & Tomato & U.S.A. & Madison & $\mathrm{NC}$ & 2014 & MK928800 \\
\hline 132 & & 87 & AsAlH11 & Tomato & U.S.A. & Madison & $\mathrm{NC}$ & 2014 & MK928801 \\
\hline 133 & & 88 & AsAlH11 & Tomato & U.S.A. & Madison & $\mathrm{NC}$ & 2014 & MK928802 \\
\hline 134 & & 89 & AsAlH10 & Tomato & U.S.A. & Madison & $\mathrm{NC}$ & 2014 & MK928803 \\
\hline 135 & & 92 & AsAlH10 & Tomato & U.S.A. & Madison & $\mathrm{NC}$ & 2014 & MK928804 \\
\hline 136 & & 93 & AsAlH2/H3 & Tomato & U.S.A. & Madison & $\mathrm{NC}$ & 2014 & MK928805 \\
\hline 137 & & 94 & AsAlH9 & Tomato & U.S.A. & Madison & $\mathrm{NC}$ & 2014 & MK928806 \\
\hline 138 & & 95 & AsAlH11 & Tomato & U.S.A. & Madison & $\mathrm{NC}$ & 2014 & MK928807 \\
\hline 139 & & 96 & AsAlH2/H3 & Tomato & U.S.A. & Madison & $\mathrm{NC}$ & 2014 & MK928808 \\
\hline
\end{tabular}


TABLE 1. (Continued from previous page)

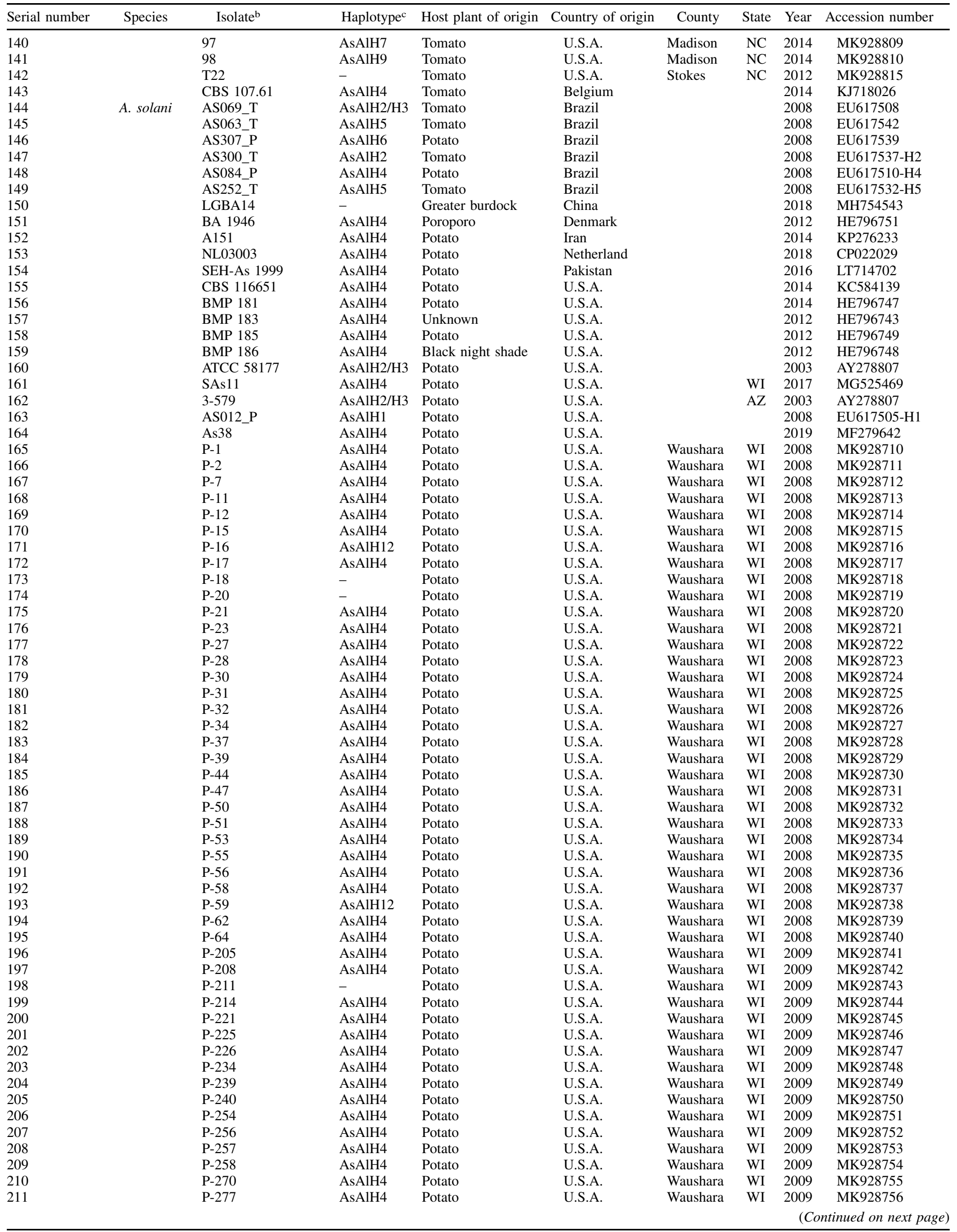


TABLE 1. (Continued from previous page)

\begin{tabular}{|c|c|c|c|c|c|c|c|c|c|}
\hline Serial number & Species & Isolate $^{\mathrm{b}}$ & Haplotype $^{c}$ & Host plant of origin & Country of origin & County & State & Year & Accession number \\
\hline 212 & A. porri & CBS 116698 & - & Onion & U.S.A. & & & 2014 & KC584132 \\
\hline 213 & A. grandis & CBS 116695 & AsAlH1 & Potato & U.S.A. & & & 2014 & KJ718070 \\
\hline 214 & $\begin{array}{l}\text { A. tomatophila } \\
(=\text { A. linariae })\end{array}$ & BA 1523 & AsAlH2/H3 & Tomato & Australia & & & 2012 & HE79673 \\
\hline 215 & & HaAt4 & AsAlH4 & Sunflower & China & & & 2019 & MK411013 \\
\hline 216 & & BA 1526 & AsAlH2/H3 & Tomato & New Zealand & & & 2012 & HE796740 \\
\hline 217 & & MF-P585011 & AsAlH4 & Tomato & Russia & & & 2014 & KJ397987 \\
\hline 218 & & MF-P138061 & AsAlH2/H3 & Tomato & Russia & & & 2014 & KJ397985 \\
\hline 219 & & BA 1443 & AsAlH2/H3 & Tomato & U.S.A. & & IN & 2012 & HE796739 \\
\hline 220 & & BA 1528 & AsAlH2/H3 & Tomato & U.S.A. & & PA & 2012 & HE796736 \\
\hline 221 & & BA 1527 & AsAlH2/H3 & Tomato & Venezuela & & & 2012 & HE796737 \\
\hline
\end{tabular}

Alternaria spp. from tomato is limited. The outbreaks of brown spot, caused by A. alternata and EB caused by A. solani on potato have increased recently in WI (Ding et al. 2019; Weber and Halterman 2012). However, it is unknown whether recurrent disease epidemics in tomato and potato in NC and WI are caused by the same or different haplotypes within each species of Alternaria. To address this question, we used coalescent genealogical approaches to obtain phylogenetically informative data derived from DNA sequences of Alternaria spp. using two nuclear loci: $G P D H$, RNA polymerase second largest subunit (RPB2) (Liu and Hall 2004), and the ITS region.

The main objective of this study was to compare the relative level of DNA polymorphisms of GPDH, ITS, and RPB2 within each species and determine haplotype diversity and infer phylogenetic relationships of these isolates with publicly available sequences of the GPDH gene of Alternaria spp. from different countries. GPDH sequences were selected because this nuclear gene has been used previously to analyze the phylogenetic analysis of $A$. alternata and A. solani, respectively (Ding et al. 2019; Lourenço et al. 2009). A haplotype herein is defined as a set of DNA variations or single nucleotide polymorphisms (SNPs) found on the gene regions (Rebbeck et al. 2004). The findings of this study are important for understanding the phylogenetic relationships among isolates of Alternaria spp. recovered from tomato and potato and for devising disease resistance breeding programs.

\section{MATERIALS AND METHODS}

Sample locations and collection. Tomato is mainly grown in $\mathrm{NC}$, and leaf blight symptoms caused by A. alternata and $A$. linariae in tomato were found at late and early stages of plant growth, respectively. The northeast and central $\mathrm{NC}(\sim 100 \mathrm{~m}$ above sea level) regions have a warm humid and coastal climate and mild winters. A. alternata was found to be sporadic in these regions in $\mathrm{NC}$, and we intentionally sampled this species from the northeast and central region between 2012 and 2014 (Table 1). In the case of A. alternata, samples from Stokes County were mainly collected from heirloom tomatoes grown on an organic farm while samples from Pender and Sampson counties were collected from commercial hybrids. The western NC represents high elevations (>600 m above sea level) and has a temperate climate with cold winters and rainy summers. A. linariae was endemic in western NC and leaf samples were intentionally collected from major tomato-growing counties during the early season in 2014. The EB symptoms showing circular lesions with concentric rings surrounded by a yellow hallow caused by A. linariae were commonly found in hybrid tomato and sampled from five counties: Haywood, Henderson, Macon, Madison, and Swain using a stratified random sampling approach (Cochran 1977). Up to four young leaflets with EB lesions were sampled from each plant and ranged from 20 to 60 samples per county. The procedures for isolation of A. alternata and A. linariae from tomato have been described previously (T. B. Adhikari, S. Timilsina, K. Bhattarai, I. Meadows, D. Halterman, and F. J. Louws, unpublished data).
Weather conditions in WI typically include extreme cold winters and warm summers and tomato are rarely grown in WI. A. alternata isolates were isolated from potato in WI but they only considered $A$. alternata as an opportunistic pathogen (Weber and Halterman 2012). EB caused by A. solani was an endemic disease mainly in Waushara County, WI. Isolation and purification of $A$. solani isolates were performed previously (Weber and Halterman 2012). In all, 152 single-spore isolates of Alternaria spp. were collected and used in this study (Table 1). Population herein is referred to as samples or isolates collected from a location or county.

Morphological characterization. Each isolate was transferred to acidified potato dextrose agar (A-PDA) medium ( $4 \mathrm{~g}$ of potato starch, $20 \mathrm{~g}$ of dextrose, and $15 \mathrm{~g}$ of agar/liter of distilled water and amended with two antibiotics: ampicillin [0.06 g/liter] and rifampicin [0.024 g/liter]). Morphological characters (e.g., conidia type, septate, presence and number of beaks) of the isolates were examined under a binocular stereomicroscope (Leica Microsystems, Wetzlar, Germany). Species identification based on morphology was performed as described previously (Simmons 2007; Woudenberg et al. 2014).

Molecular characterization. Each culture was transferred to $50 \mathrm{ml}$ of Difco potato sucrose broth medium in Erlenmeyer flasks that were continuously agitated at $110 \mathrm{rpm}$ at room temperature. After 7 days, mycelium was transferred to 2-ml centrifuge tubes and lyophilized. To obtain the fine powder, the lyophilized-mycelium tissues were ground using a microtube homogenizer (Model D1030-E, Beadbug, Benchmark Scientific Inc., Edison, NJ) at $400 \mathrm{rpm}$ for $3 \mathrm{~min}$. Genomic DNA was extracted using the DNeasy Plant Mini kit (Qiagen, Valencia, CA) following the manufacturer's instructions. The DNA concentration was quantified using a spectrophotometer (ND-1000, NanoDrop Technologies Inc., Wilmington, DE) and adjusted to a concentration of DNA at $10 \mathrm{ng} / \mu \mathrm{l}$ for each isolate. In the previous study (Gannibal et al. 2014), OAsF7 and OAsR6 primers were used to differentiate morphologically similar large-spores Alternaria spp. such as A. solani and A. linariae. We used $A$. solani-specific primers OAsF7 (5'-CGAC GAGTAAGTTGCCCTCA-3') and OAsR6 (5'-TGTAGGCGTCA GAGACACCATT- $3^{\prime}$ ), which amplified the Alt al genomic region only in A. solani, and another primer set, OAtF4 (5'-TGCGGCT TGCTGGCTAAGGT-3') and OAtR2 (5'-CAGTCGATGCGGCC GTCA-3'), which amplified DNA fragment from the calmodulin encoding gene of A. linariae and some other large-spored Alternaria species excluding $A$. solani (Gannibal et al. 2014).

PCR assays and sequencing. Three nuclear loci: $G P D H$, $R P B 2$, and the ITS region were selected because some of these genes were used previously to compare patterns of genetic variation of $A$. solani from tomato and potato in Brazil (Lourenço et al. 2009) and A. solani and A. alternata from potato in WI (Ding et al. 2019). Partial sequences of $G P D H, R P B 2$, and the ITS region were amplified using primer sets GPD-F/GPD-R (Berbee et al. 1999), RPB2-F/RPB2-R (Woudenberg et al. 2015), and ITS4 and ITS5 (White et al. 1990), respectively. A 25- $\mu$ l mixture was used for the amplification and each PCR contained $8.5 \mu \mathrm{l}$ of sterile distilled water, $2 \mu \mathrm{l}$ of $10 \mathrm{ng} / \mu \mathrm{l}$ genomic DNA, $1 \mu \mathrm{l}$ each of $10 \mu \mathrm{M}$ reverse and 
forward primer, and $12.5 \mu \mathrm{l}$ of GoTaq Green PCR mix (Promega Inc., Madison, WI). The amplification with GPDH and ITS primer sets was performed individually using the same program: $95^{\circ} \mathrm{C}$ for $30 \mathrm{~s}$, followed by 44 cycles: $94^{\circ} \mathrm{C}$ for $15 \mathrm{~s}, 50^{\circ} \mathrm{C}$ for $30 \mathrm{~s}$, and $68^{\circ} \mathrm{C}$ for $3 \mathrm{~min}$; and final elongation of $72^{\circ} \mathrm{C}$ for $15 \mathrm{~min}$. The amplification of RPB2 was the following: $95^{\circ} \mathrm{C}$ for $30 \mathrm{~s} ; 30$ cycles: $94^{\circ} \mathrm{C}$ for $15 \mathrm{~s}, 60^{\circ} \mathrm{C}$ for $30 \mathrm{~s}, 68^{\circ} \mathrm{C}$ for $3 \mathrm{~min}$ and final extension $72^{\circ} \mathrm{C}$ for $7 \mathrm{~min}$. The quality of the PCR product of each sample and fragment of the expected size was confirmed by electrophoresis on a $1.5 \%$ agarose gel (wt/vol). PCR product purification was done using ExoSAP-IT PCR product cleanup reagent (Affymetrix, Inc., Santa Clara, CA). Six microliters of PCR product and $1 \mu \mathrm{l}$ of $10 \mu \mathrm{M}$ reverse or forward primer were added to each reaction and sent for sequencing at Genomic Sciences Laboratory, North Carolina State University, Raleigh, NC.

Sequence analysis and alignments. Raw sequence data were visually evaluated for quality using Geneious ver. 11.1.4 (1 May 2018; Biomatters Ltd., Auckland, New Zealand). Consensus sequences were generated and aligned using eight iterations of MUSCLE (Edgar 2004). Base substitutions were grouped as phylogenetically informative or uninformative and each polymorphic site received a specific site number on the consensus sequence.

Nucleotide diversity and haplotype assignment within species. The relative degree of DNA polymorphisms for each gene sequence data set was examined among isolates of each species. Nucleotide diversity at the three loci: GPDH, ITS, and RPB2 were determined using DNA Sequence Polymorphism software (DNASP) ver.6 (Rozas et al. 2017). To arbitrarily assign locusspecific and species-specific haplotype, sequence data sets were generated for each locus separately. Three data sets were mined to identify haplotype within species in this study: (i) $\mathrm{AaH} 1$ to AaH6 haplotype for $R P B 2$ sequences for all 46 isolates of A. alternata; (ii) $\mathrm{AaH} 1$ to $\mathrm{AaH} 5$ haplotype for $G P D H$ sequences for all 48 isolates of A. alternata; and (iii) AsAlH1 to AsAlH12 haplotype for GPDH sequences for all 106 isolates of $A$. solani and A. linariae. For comparisons, A. solani and A. linariae haplotypes AsAlH1 to AsAlH6 were like previously reported haplotype nomenclature
(Lourenço et al. 2009). For each gene sequence data set, the SNAP Map program (Price and Carbone 2005) was used to collapse nucleotide sequences into haplotypes (Aylor et al. 2006). The SNAP Workbench Java program package was used to analyze gene genealogies and population parameters (Price and Carbone 2005). Compatibility matrices were developed for haplotypes that share a common ancestry to examine the overall or conflict among variable sites in DNA sequence alignments as described previously (Jakobsen et al. 1997). The population mutation parameter per nucleotide site $\Theta$ using Watterson's (1975) $\Theta_{w}$, based on the number of segregating sites $(\mathrm{S})$, and the average pairwise nucleotide diversity $(\pi)$ (Tajima 1989) were estimated using DNASP ver.5 (Librado and Rozas 2009) for each locus across isolates of each species.

Tests of neutrality. Neutrality test statistics were estimated with Tajima's D (TD) (Tajima 1989), Fu and Li's D (FLD), Fu and Li's F (FLF) (Fu and Li 1993), and Fu's F (Fu 1997) using 5,000 permutations (Kimura 1980). Based on these tests, if only TD, FLD, and FLF were significant and Fu's $F$ was nonsignificant, this indicated background selection (Fu 1997). If only Fu's $F$ was significant, this suggested population growth. Likewise, when TD and Fu's $F$ test values were negative and nonsignificant, it indicated an excess of mutations. Positive values suggested a population division or background selection (Carbone et al. 2007). These four neutrality tests were calculated for all isolates of each species for each locus and the combined data of $A$. linariae and A. solani $(N=106)$.

Phylogenetic inference. To determine genetic relationships among isolates within species, both ends of each gene sequences were trimmed to the same length before concatenating the sequences. The concatenation of the three gene sequences of each isolate was used for phylogenetic analysis. Phylogenetic relationships were analyzed using maximum likelihood (ML). For ML analysis, PAUP* ver. $4 . b 10$ (Swofford 2004) was used with resampling estimated log-likelihood of 1,000 bootstrap replicates. Multilocus tree building was performed using the Tamura-Nei genetic distance model (Tamura and Nei 1993). Metadata were analyzed with the Tamura-Nei model using the Tree-Based

TABLE 2. Variable bases in two nuclear genes, glyceraldehyde-3-phosphate dehydrogenase (GPDH) and RNA polymerase second largest subunit (RPB2), and the internal transcribed spacer (ITS) rDNA region were analyzed on the 152 isolates of three Alternaria spp. from tomato in North Carolina (NC) and potato in Wisconsin (WI)



${ }^{a}$ Data refer to polymorphic sites from each locus and nucleotide consensus based on majority agreement at each variable location. In all, 152 isolates of Alternaria spp. were collected and analyzed in this study (Table 1). Among these, A. alternata isolates $(N=46)$ were collected from mainly heirloom tomato in the northeast and central NC. A. linariae $(N=59)$ were collected from hybrid tomato in the western NC. A. solani isolates $(N=47)$ were collected from potato cultivars and lines in Waushara County, WI. $\mathrm{Y}=\mathrm{C} / \mathrm{T}, \mathrm{S}=\mathrm{G} / \mathrm{C}, \mathrm{W}=\mathrm{A} / \mathrm{T}, \mathrm{M}=\mathrm{A} / \mathrm{C}$, and $\mathrm{R}=\mathrm{A} / \mathrm{G}$. 
Alignment Selector T-BAS v 2.0 (Carbone et al. 2017). Bootstrap analysis was used to determine the statistical support for each branch of trees generated with 1,000 replications. Phylogenetics was displayed in the circle tree format and the results were visualized as the outer rings of multigene ML phylogeny.

Comparison of $G P D H$ sequences between the current isolates of $A$. alternata and the global isolates. The GPDH gene sequences of 46 isolates of A. alternata from tomato in NC (Table 1) were compared with publicly available $G P D H$ gene sequences of international isolates downloaded from GenBank (https://www.ncbi.nlm.nih.gov/genbank/). For haplotype comparisons, sequences of 15 representative isolates of $A$. alternata from potato from the previous study of Ding et al. (2019) were retrieved. The isolates included were SAa1 (accession no. MG525459), SAa2 (MG525460), SAa3 (MG525461), SAa4 MG525462), SAa5 (MG525463), SAa6 (MG525464), SAa7 (MG525465), SAa8 (MG525466), SAa9 (MG525467), and SAa10 (MG525468) collected from Grand Marsh, Hancock, and Plover counties from WI in 2017, and Aa35 (MF279611), Aa52 (MF279619), Aa60 (MF279624), Aa70 (MF279631), and Aa79 (MF279640) collected from Hancock and Plover counties from WI in 2012. Also, sequences of the 17 international isolates of $A$. alternata collected from various host plants were downloaded from GenBank and included for comparisons (Table 1). These isolate sequences were from China $(N=8)$, Iran $(N=3)$, Italy $(N=1)$, Serbia $(N=3)$, and South Korea $(N=2)$. The results were visualized in T-BAS v.2.0 (Carbone et al. 2017).

Comparison of $G P D H$ sequences between the current isolates of $A$. linariae and $A$. solani and the global isolates. $G P D H$ gene sequences of the 59 isolates of $A$. linariae sampled from tomato in NC and 47 isolates of $A$. solani from potato were analyzed (Table 1). Additionally, six isolate sequences AS063_T (accession no. EU617542), AS307_P (EU61539), AS084_P (EU617510), AS069_T (EU17508), AS300_T (EU617537), and AS252_T (EU617532) of A. solani from Brazil were included for haplotype comparisons (Lourenço et al. 2009). For A. linariae, $G P D H$ sequences downloaded from GenBank were from Algeria $(N=4)$ and Belgium $(N=1)$. For $A$. solani, $G P D H$ sequences were from China $(N=1)$, Denmark $(N=1)$, Iran $(N=1)$, Netherland
$(N=1)$, Pakistan $(N=1)$, and the United States $(N=10)$. Also, $A$. tomatophila (syn. A. linariae) isolate sequences used were one each from Australia, China, New Zealand, and Venezuela and two each from Russia and the United States. We also included sequences of $A$. porri and A. grandis from the United States (Table 1). FASTA format of each isolate was trimmed and aligned using Geneious ver. 11.1.4. Tree outputs were assembled for each isolate using the T-BAS v.2.0 as described previously (Carbone et al. 2017).

Comparison of the $R P B 2$ and $G P D H$ locus-based haplotypes of Alternaria spp. identified in the current study with publicly available Alternaria whole-genome sequences. We retrieved publicly available whole-genome sequence data of three isolates: BMP 0185 (A. solani) (Dang et al. 2015), HWC-128 (A. solani; accession no. JRWV00000000), and SRC11rK2f (A. alternata; accession no. GCA_001642055) were retrieved from GenBank and compared with the haplotypes identified in the current study. Sequence data were evaluated using Geneious ver. 11.1.4 (1 May 2018; Biomatters Ltd., Auckland, New Zealand) and aligned using MUSCLE (Edgar 2004). Base substitutions were between the RPB2 and GPDH locus-based haplotypes and whole-genome isolates were compared and grouped at a specific site on the consensus sequences.

\section{RESULTS}

Morphological characterization. Three Alternaria spp. can cause leaf blight symptoms with the same appearance of lesions in both tomato and potato in NC and WI. In total, 152 isolates were collected and identified as Alternaria spp. based on the microscopic examination of morphological traits. For purified isolates grown on A-PDA, colonies with aerial mycelium were dense and black in reverse. Dark brown conidia were small and large, and separated with or without a long beak. Based on the size of the conidia and the presence of beak, the isolates of Alternaria spp. were classified into two groups: small-spore and large-spore. All samples collected from the north and central NC were small-spored without beak and were identified as A. alternata. Similarly, all samples collected from the western NC were large-spored with long multiple beaks and

TABLE 2. (Continued from previous page)

\begin{tabular}{|c|c|c|c|c|c|c|c|c|c|c|c|c|c|c|}
\hline \multicolumn{15}{|c|}{ GPDH (483 nt) polymorphic sites } \\
\hline 154 & 155 & 177 & 179 & 186 & 324 & 339 & 400 & 409 & 424 & 436 & 448 & 454 & 478 & \\
\hline $\mathrm{C}$ & $\mathrm{T}$ & $\mathrm{C}$ & $\mathrm{W}$ & $\mathrm{C}$ & $\mathrm{T}$ & $\mathrm{T}$ & $\mathrm{T}$ & $\mathrm{T}$ & $\mathrm{T}$ & $\mathrm{T}$ & $\mathrm{C}$ & $\mathrm{C}$ & $\mathrm{C}$ & \\
\hline \multicolumn{15}{|c|}{ ITS (474 nt) polymorphic sites } \\
\hline 332 & 334 & 335 & 339 & 340 & 342 & 347 & 366 & 410 & 417 & 418 & 422 & 423 & 441 & 442 \\
\hline $\mathrm{G}$ & $\mathrm{C}$ & - & A & G & $\mathrm{T}$ & $\mathrm{T}$ & A & A & A & $\mathrm{T}$ & - & - & $\mathrm{T}$ & $\mathrm{T}$ \\
\hline \multicolumn{15}{|c|}{$R P B 2$ (699 nt) polymorphic sites } \\
\hline 139 & 156 & 159 & 183 & 204 & 219 & 222 & 231 & 234 & 261 & 267 & 273 & 318 & 351 & 357 \\
\hline $\mathrm{T}$ & C & C & C & G & $\mathrm{T}$ & G & C & C & A & C & C & C & G & C \\
\hline $\mathrm{T}$ & $\mathrm{C}$ & $\mathrm{C}$ & $\mathrm{T}$ & G & $\mathrm{T}$ & G & $\mathrm{C}$ & $\mathrm{C}$ & A & $\mathrm{C}$ & $\mathrm{C}$ & $\mathrm{C}$ & G & $\mathrm{C}$ \\
\hline $\mathrm{C}$ & $\mathrm{T}$ & $\mathrm{T}$ & C & A & Y & A & $\mathrm{T}$ & $\mathrm{T}$ & G & Y & Y & A & A & $\mathrm{T}$ \\
\hline
\end{tabular}


were assigned to A. linariae, while all large-spored conidia with a single long beak collected from potato in WI were A. solani.

Molecular characterization. As expected, the primer set OAsF7/OAsR6 amplified a $164 \mathrm{bp}$ fragment from A. solani only, while OAtF4 and OAtR2 primers amplified a 438-bp DNA fragment from A. linariae (Gannibal et al. 2014). PCR assay based on DNA samples from tomato and potato confirmed the isolates to be A. linariae and A. solani, respectively.

Tests of neutrality. Nucleotide polymorphisms analyzed through gene-by-gene comparisons in each species included 483 nucleotides for $G P D H, 474$ for ITS, and 669 for $R P B 2$ and concatenated data for the three genes was 1,626 bp in length (Table 2 ). Intraspecific variability was detected in each species across the isolates analyzed. By comparisons across three species, 30, 31, and 59 nucleotide polymorphisms were identified in the GPDH, ITS, and $R P B 2$ genes, respectively (Table 2 ). Nucleotide diversity $(\pi)$ estimates in three species ranged from 0.00088 to 0.00264 for the GPDH gene; from 0 to 0.00019 for the ITS region, and 0 to 0.00674 for the RPB2 gene (Table 3 ). For the combined $A$. linariae and $A$. solani populations, $\pi$ values for the GPDH, ITS, and RPB2 genes were 0.00278, 0.00004, and 0.01079 , respectively. The $G P D H$ and $R P B 2$ genes had a higher number of segregating sites $(\mathrm{S})$ and mean mutation parameters per site (Watterson's $\Theta_{\mathrm{w}}$ ) than the ITS region (Table 3 ).

We used four neutrality tests to determine whether the data departed from an equilibrium model of neutral evolution and provided insight into an indication of recent population expansion. In A. alternata, most of the neutrality test values were negative for the GPDH locus and the ITS region (Table 3). Although FLD and FLF estimates were negative, these two values were significant $(P \leq$ 0.05 ) for the $G P D H$ gene, suggesting an excess of recent mutations in the A. alternata population. In the case of $A$. linariae, TD, FLD, and Fu's $F$ values were negative for the RPB2 gene, and only the FLF estimate was positive. For $A$. solani, all four estimates were negative. However, FLF values were significant for both GPDH and ITS within selective species (Table 3 ). For the combined A. linariae and $A$. solani, TD and FLF statistics were positive and significant for the $R P B 2$ gene. In contrast, all four neutrality test statistics (TD, FLD, FLF, and Fu's F) were negative for both GPDH and ITS genes, but TD, FLD, and FLF values for the GPDH gene were significant (Table 3).
Haplotype identification within species. For the ITS gene sequences, low nucleotide polymorphism was observed. Thus, it was less informative to identify haplotypes in all species tested. For A. alternata, the $G P D H$ gene sequence data set yielded five haplotypes ( $\mathrm{AaH} 1, \mathrm{AaH} 2, \mathrm{AaH} 3$, and $\mathrm{AaH} 4$, and one unique haplotype AaH5) of A. alternata with seven SNPs (Fig. 1; Table 4). Likewise, the GPDH gene data set yielded 12 haplotypes of $A$. solani and A. linariae with seven SNPs (Table 5; Fig. 1). Among them, six haplotypes (AsAlH7, AsAlH8, AsAlH9, AsAlH10, AsAlH11, and AsAlH12) were unique and new (Fig. 1). Intriguingly, a single SNP at position 20 led to an amino acid change from valine (Val) to leucine (Leu) in the isolates belonging to three haplotypes of A. linariae and A. solani: $\mathrm{H} 7, \mathrm{H} 8$, and $\mathrm{H} 9$ (Table 5). The $R P B 2$ gene sequences had a lower number of polymorphic sites than the GPDH locus. Therefore, at least six haplotypes (H1 to H6) were detected with 15 SNPs in A. alternata for the RPB2 sequences (Table 6). Although 15 SNPs at the RPB2 sequences were found between $A$. linariae and $A$. solani, the identified nucleotide polymorphisms were not variable enough to allow for resolution to differentiate haplotypes within A. linariae or A. solani (Table 2).

For the GPDH gene sequences, $\mathrm{AaH} 1$ to $\mathrm{AaH} 5$ were more common in A. alternata than other haplotypes in all counties in NC sampled. However, AaH1 $(N=25)$ was the most frequent haplotype in Stokes County followed by Henderson and Sampson counties (Supplementary Table S1; Fig. 1). The number of isolates detected in each haplotype in the other counties was low (between 0 and 3 ). One unique haplotype was detected in Henderson and Stokes counties $(N=4)$. Based on the $R P B 2$ gene, six haplotypes (AaH1 to AaH6) and one unique haplotype were found in A. alternata from NC (Supplementary Table S2; Fig. 1). In Stokes County, haplotype $\mathrm{AaH} 3$ was common $(N=10)$ followed by AaH5 $(N=6)$ and AaH4 $(N=5)$. In other counties, the distribution of isolates in each haplotype was low ranging from 0 to 3 .

In A. solani, AsAlH4 $(N=42)$ was exclusively found in Waushara County, WI (Supplementary Table S3; Fig. 1) followed by AsAlH12 $(N=2)$. Only one unique haplotype $(N=3)$ was found. However, no other haplotypes were detected in Waushara County, WI. In $A$. linariae, haplotypes AsAlH2/H3 were found in Haywood $(N=7)$, Macon $(N=8)$, and Madison $(N=4)$ counties (Supplementary Table S3; Fig. 1). Similarly, haplotype AsAlH7 was detected in Haywood

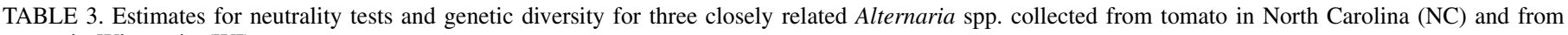
potato in Wisconsin (WI)

\begin{tabular}{|c|c|c|c|c|c|c|c|c|c|c|}
\hline Species & Host & $N^{\mathrm{a}}$ & Locus $^{b}$ & $\mathrm{~S}^{\mathrm{c}}$ & $\mathrm{TD}^{\mathrm{d}}$ & $\mathrm{FLD}^{\mathrm{d}}$ & $\mathrm{FLF}^{\mathrm{d}}$ & Fu's Fd & $\pi^{\mathrm{e}}$ & $\Theta_{w}^{f}$ \\
\hline \multirow[t]{3}{*}{ A. solani } & \multirow[t]{3}{*}{ Potato } & \multirow[t]{3}{*}{47} & $R P B 2$ & 0 & $\mathrm{NA}^{\mathrm{g}}$ & NA & NA & NA & 0.0000 & NA \\
\hline & & & ITS & 1 & -1.1 & $-2.35 * \mathrm{~h}$ & $-3.19^{*}$ & -4.08 & 0.00009 & 0.00047 \\
\hline & & & $G P D H$ & 9 & -2.24 & -3.84 & $-3.68 *$ & -2.53 & 0.00088 & 0.00422 \\
\hline \multirow[t]{3}{*}{ A. linariae } & \multirow[t]{3}{*}{ Tomato } & \multirow[t]{3}{*}{59} & $R P B 2$ & 2 & -1.44 & -2.6 & 2.5 & -1.01 & 0.0001 & 0.00062 \\
\hline & & & ITS & 0 & NA & NA & NA & NA & 0.0000 & NA \\
\hline & & & $G P D H$ & 4 & 1.04 & 0.99 & 1.15 & -1.81 & 0.00264 & 0.00179 \\
\hline \multirow[t]{3}{*}{ A. alternata } & \multirow[t]{3}{*}{ Tomato } & \multirow[t]{3}{*}{46} & $R P B 2$ & 18 & -0.47 & 0.85 & 0.8 & -0.67 & 0.00674 & 0.00588 \\
\hline & & & ITS & 2 & -1.47 & -2.49 & -2.4 & -2.91 & 0.00019 & 0.00097 \\
\hline & & & $G P D H$ & 9 & -1.9 & $-2.52 * *$ & $-2.57 * *$ & -4.93 & 0.0014 & 0.00425 \\
\hline \multirow{3}{*}{$\begin{array}{l}\text { A. linariae and A. solani } \\
\text { combined }\end{array}$} & \multirow[t]{3}{*}{ Tomato and potato } & \multirow[t]{3}{*}{106} & $R P B 2$ & 17 & $3.68 * * *$ & 0.64 & $2.04 * * *$ & 21.99 & 0.01079 & 0.00466 \\
\hline & & & $I T S$ & 1 & -1.02 & -2.05 & -1.95 & -2.27 & 0.00004 & 0.00040 \\
\hline & & & $G P D H$ & 13 & $-1.24^{*}$ & $-3.3 *$ & $-2.94 * *$ & -4.32 & 0.00278 & 0.0038 \\
\hline
\end{tabular}


were collected from mainly heirloom tomato in the northeast and central NC. A. linariae $(N=59)$ were collected from hybrid tomato in the western NC. $A$. solani isolates $(N=47)$ were collected from potato cultivars and lines in Waushara County, WI.

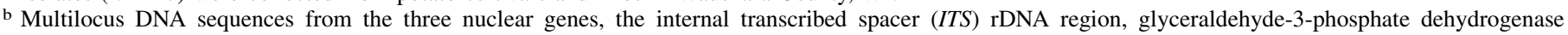
$(G P D H)$, and RNA polymerase second largest subunit (RPB2), were sequenced and analyzed. Unique sequence determined by nucleotide polymorphism(s) present.

c $S=$ number of segregating sites calculated according to Watterson (1975).

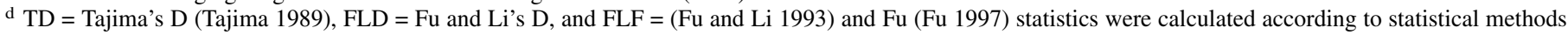
described previously.

e $\pi=$ nucleotide diversity was calculated as described previously (Tajima 1989).

f For each analysis, $\Theta_{\mathrm{w}}$ is the population mutation parameter per nucleotide estimated according to Watterson (1975).

g NA $=$ not applicable.

$\mathrm{h} *, * *$, and $* * *$ indicate significance at $P<0.10, P<0.05$, and $P>0.01$, respectively. 
$(N=1)$, Madison $(N=1)$, and Swain $(N=8)$ counties. Haplotype AsAlH8 was rare but it was found only in Madison and Swain counties. Likewise, haplotypes $\mathrm{H} 9$ and $\mathrm{H} 10$ were detected only in Madison and Macon counties. Haplotype AsAlH11 was present in Haywood and Madison counties. Interestingly, haplotypes AsAlH4 and AsAlH12 were absent in A. linariae in NC. One unique haplotype was detected in Haywood $(N=2)$, Macon $(N=3)$, and Swain $(N=1)$ counties (Supplementary Table S3; Fig. 1$)$. At the $R P B 2$ locus, 15,43 , and 44 nucleotide variations occurred between A. linariae and A. solani, A. linariae and A. alternata, and A. solani and A. alternata, respectively (Supplementary Table S4). Interestingly, all isolates of $A$. linariae analyzed had similar SNPs at

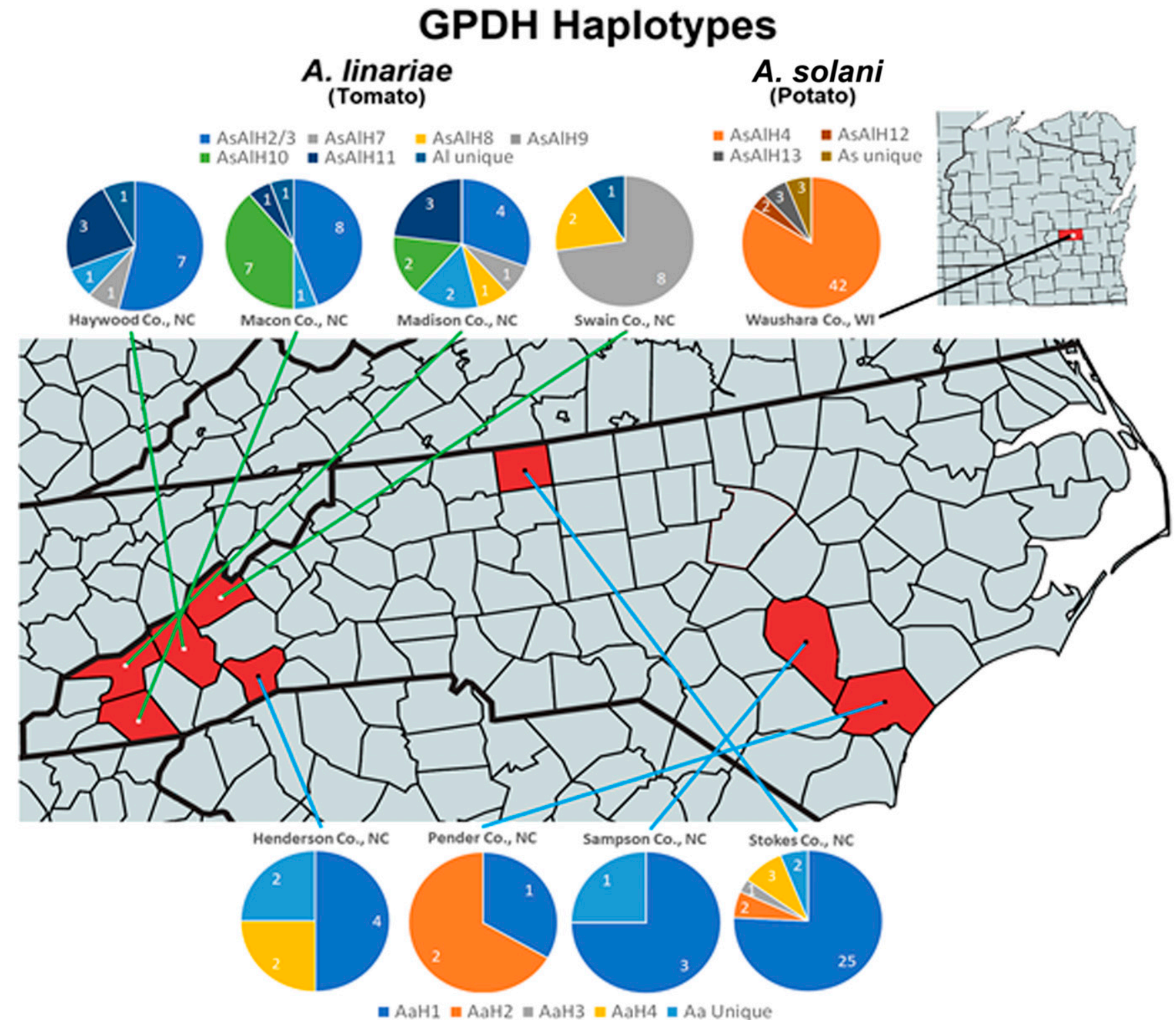

A. alternata GPDH Haplotypes

(Tomato)
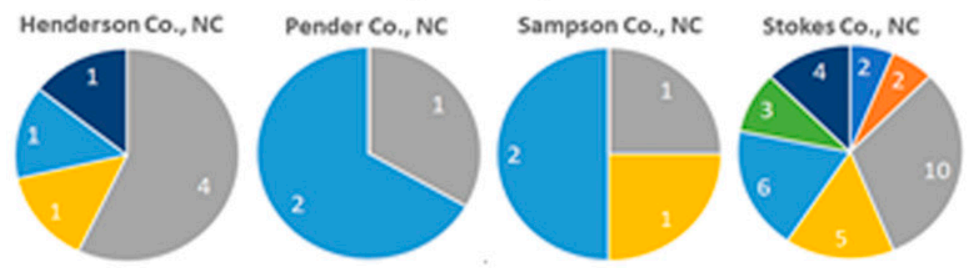

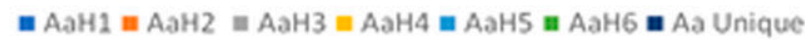

\section{A. alternata RPB2 Haplotypes}

Fig. 1. Identification and distribution of haplotypes $(\mathrm{H})$ of Alternaria spp. analyzed using the single-copy two nuclear genes: the glyceraldehyde-3-phosphate dehydrogenase $(G P D H)$ and RNA polymerase second largest subunit (RPB2). In all, 152 isolates of three closely related Alternaria spp. collected from the sampled counties in tomato- and potato-producing area (red spots on the map) in North Carolina (NC) and Wisconsin (WI). Numbers in pie charts indicate the frequency of isolates from each haplotype from each species of Alternaria. 
the $R P B 2$ region and had a poor resolution to distinguish isolates within this species. Similarly, for $A$. solani isolate sequences were too conserved and did not distinguish isolates within A. solani. However, there was an apparent separation of $A$. linariae isolates and those of $A$. solani isolates based on the metadata profile of the sequences mined from the RPB2 locus (Table 2; Supplementary Table S4).

Gene genealogy. The rooted trees generated from the RPB2 gene sequences revealed that haplotype networks showed mutations along with clades specific to A. alternata; however, these gene

TABLE 4. Nucleotide polymorphisms in the glyceraldehyde-3-phosphate dehydrogenase $(G P D H)$ among haplotypes of Alternaria alternata isolates $(N=$ 46) collected from tomato in North Carolina

\begin{tabular}{lccccccc}
\hline & \multicolumn{7}{c}{$G P D H^{\mathrm{a}}(488 \mathrm{nt})$ polymorphic sites } \\
\cline { 2 - 8 } Haplotypes & 47 & 65 & 127 & 146 & 147 & 156 & 187 \\
\hline AaH1 & $\mathrm{C}$ & $\mathrm{C}$ & $\mathrm{C}$ & $\mathrm{C}$ & $\mathrm{C}$ & $\mathrm{C}$ & $\mathrm{C}$ \\
$\mathrm{AaH} 2$ & $\mathrm{~T}$ & $\mathrm{C}$ & $\mathrm{C}$ & $\mathrm{C}$ & $\mathrm{C}$ & $\mathrm{C}$ & $\mathrm{T}$ \\
$\mathrm{AaH} 3$ & $\mathrm{C}$ & $\mathrm{C}$ & $\mathrm{C}$ & $\mathrm{C}$ & $\mathrm{A}$ & $\mathrm{T}$ & $\mathrm{C}$ \\
$\mathrm{AaH} 4$ & $\mathrm{C}$ & $\mathrm{T}$ & $\mathrm{C}$ & $\mathrm{T}$ & $\mathrm{C}$ & $\mathrm{C}$ & $\mathrm{C}$ \\
AaH5 & $\mathrm{C}$ & $\mathrm{C}$ & $\mathrm{T}$ & $\mathrm{C}$ & $\mathrm{C}$ & $\mathrm{C}$ & $\mathrm{C}$ \\
\hline
\end{tabular}

a Nucleotide polymorphisms at the GPDH gene sequences of A. alternata. The consensus sequence of variable nucleotides of each haplotype for the $G P D H$ locus. Sequences are presented for the five haplotypes and the number indicates the base position of each variable site. A. alternata isolates collected from mainly heirloom tomato were from Henderson, Pender, Sampson, and Stokes counties.

TABLE 5. Nucleotide polymorphisms in the glyceraldehyde-3-phosphate dehydrogenase $(G P D H)$ locus among haplotypes of Alternaria linariae $(N=59)$ and A. solani $(N=47)$ collected from tomato and potato in North Carolina and Wisconsin, respectively

\begin{tabular}{|c|c|c|c|c|c|c|c|c|}
\hline \multirow[b]{2}{*}{ Haplotypes $^{\mathrm{b}}$} & \multirow[b]{2}{*}{ Host } & \multicolumn{7}{|c|}{$G P D H^{\mathrm{a}}(488 \mathrm{nt})$ consensus sequence } \\
\hline & & 15 & 18 & $20^{c}$ & 23 & 27 & 180 & 391 \\
\hline AsAlH2/H3 & Tomato & $\mathrm{T}$ & - & $\mathrm{G}$ & $\mathrm{G}$ & - & A & - \\
\hline AsAlH4 & Potato & $\mathrm{C}$ & - & $\mathrm{G}$ & $\mathrm{G}$ & - & $\mathrm{A}$ & - \\
\hline AsAlH7 & Tomato & $\mathrm{C}$ & - & $\mathrm{C}$ & $\mathrm{G}$ & - & $\mathrm{A}$ & - \\
\hline AsAlH8 & Tomato & $\mathrm{C}$ & - & $\mathrm{C}$ & $\mathrm{T}$ & - & A & - \\
\hline AsAlH9 & Tomato & $\mathrm{T}$ & - & $\mathrm{C}$ & $\mathrm{G}$ & - & A & - \\
\hline AsAlH10 & Tomato & $\mathrm{T}$ & - & $\mathrm{G}$ & $\mathrm{G}$ & - & $\mathrm{T}$ & - \\
\hline AsAlH11 & Tomato & $\mathrm{T}$ & - & $\mathrm{G}$ & $\mathrm{G}$ & - & A & $\mathrm{G}$ \\
\hline AsAlH12 & Potato & $\mathrm{C}$ & $\mathrm{C}$ & G & $\mathrm{G}$ & $\mathrm{T}$ & A & - \\
\hline \multicolumn{9}{|c|}{$\begin{array}{l}\text { a Consensus sequence of variable nucleotides of each haplotype for the GPDH } \\
\text { locus. } \\
\text { b. linariae isolates from hybrid tomato were collected from Haywood, } \\
\text { Macon, Madison, and Swain counties. A. solani isolates }(N=47) \text { were } \\
\text { collected from potato cultivars and lines in Waushara County, WI. }\end{array}$} \\
\hline
\end{tabular}

sequences were not variable enough to allow for resolution among the isolates within $A$. solani and A. linariae to form discrete subbranches (Fig. 2A). Based on the RPB2 locus sequence, high bootstrap score (97\%) supported haplotypes $\mathrm{AaH} 4, \mathrm{AaH} 5$, and AaH6 network and appeared to be independent; however, the remaining haplotypes (bootstrap score $>58 \%$ ) $\mathrm{AaH} 1, \mathrm{AaH} 2$, and $\mathrm{AaH} 3$ were likely divergent from other haplotypes. Sequences of the two representative isolates of $A$. linariae (isolate 1 ) and $A$. solani (P-2) were located in two branches but had no discernible bootstrap score $(100 \%)$ between these two isolates. The patterns of haplotype branches based on ML analysis for the GPDH gene sequences broadly separated three species into two clades (Fig. 2B). The top clade contained the A. alternata haplotypes: (AaH1 to $\mathrm{AaH} 4$ [bootstrap score $>74 \%$ ]) while another clade consisted of the two haplotypes (AsAl12 and AsAlH4 [score 100\%]) of A. solani and six new haplotypes (AsAl H7 to AsAl H11 located at the bottom belonging to A. linariae) (Fig. 2B).

Phylogenetic analysis. In the previous studies (Ding et al. 2019; Woudenberg et al. 2015), single-gene phylogenetic analyses could not separate isolates of small-spored Alternaria into groups. In this study, phylogenetic analyses based on the concatenation of three nuclear loci (GPDH, ITS, and RPB2) sequences showed evolutionary diversity within each species (Fig. 3). ML analysis of A. alternata isolates placed them into few clades. Although the tree topologies identified eight haplotypes (Fig. 2B), combined sequence data within isolates of $A$. linariae and $A$. solani appeared to represent monophyletic species with $100 \%$ bootstrap value (Fig. 3). No association between haplotype or species and host geographic locations was observed. Using the multigene phylogeny analyses, there was no cluster detected by location in $A$. alternata isolates collected from three locations: Grand Marsh, Hancock, and Plover from potato in WI (Ding et al. 2019). A. alternata genotype 1A was predominantly found in most locations sampled from potato in WI.

Comparison between Alternaria spp. GPDH locus-based haplotypes of the current study and global isolates. The phylogenetic relationships among global isolates of Alternaria spp. were inferred by analysis of $G P D H$ sequences because both ITS and $R P B 2$ sequences in the data set were too invariable for accurate phylogeny. Therefore, we compared the GPDH sequences of 46 isolates of $A$. alternata with 22 global isolate sequences from different countries. Similarly, sequences of 59 isolates of $A$. linariae from tomato and sequences of 47 isolates of A. solani with 26 sequences from the previous studies (Ding et al. 2019; Lourenço et al. 2009) and GenBank (https://www.ncbi.nlm.nih.gov/genbank/) were downloaded. A. alternata metadata revealed that haplotype AaH1 exhibited the highest frequency within the GPDH sequences from $\mathrm{NC}$ and other countries and formed similar network topologies (Fig. 4). On the other hand, haplotypes AaH3, AaH5, AaH9, andAaH10 exhibited the lowest frequency among the GPDH sequences from tomato in NC. These haplotypes were not present

TABLE 6. Nucleotide polymorphisms in the RNA polymerase second largest subunit $(R P B 2)$ locus among haplotypes of Alternaria alternata $(N=46)$ collected from tomato in North Carolina

\begin{tabular}{|c|c|c|c|c|c|c|c|c|c|c|c|c|c|c|c|}
\hline \multirow[b]{3}{*}{ Haplotypes $^{\mathrm{b}}$} & \multicolumn{15}{|c|}{$R P B 2^{\mathrm{a}}$ (699 nt) consensus sequence } \\
\hline & 3 & 57 & 108 & 127 & 219 & 267 & 273 & 367 & 483 & 519 & 594 & 621 & 651 & 693 & 699 \\
\hline & $\overline{\mathrm{R}}$ & $\overline{\mathrm{G}}$ & $\overline{\mathrm{T}}$ & $\overline{\mathrm{C}}$ & $\bar{Y}$ & $\bar{Y}$ & $\bar{C}$ & $\mathrm{C}$ & $\mathrm{C}$ & $\mathrm{R}$ & $\mathrm{T}$ & $\bar{A}$ & $\overline{\mathrm{A}}$ & $\overline{\mathrm{A}}$ & $\bar{Y}$ \\
\hline $\mathrm{AaH} 2$ & A & A & $\mathrm{T}$ & $\mathrm{C}$ & $\mathrm{C}$ & $\mathrm{T}$ & C & $\mathrm{C}$ & C & A & $\mathrm{T}$ & A & A & A & $\mathrm{T}$ \\
\hline $\mathrm{AaH} 3$ & A & G & $\mathrm{T}$ & $\mathrm{C}$ & $\mathrm{C}$ & $\mathrm{T}$ & C & $\mathrm{C}$ & $\mathrm{C}$ & A & $\mathrm{T}$ & A & A & A & $\mathrm{T}$ \\
\hline $\mathrm{AaH} 4$ & C & G & $\mathrm{T}$ & $\mathrm{C}$ & $\mathrm{T}$ & $\mathrm{C}$ & $\mathrm{T}$ & $\mathrm{C}$ & C & G & $\mathrm{T}$ & A & A & $\mathrm{G}$ & $\mathrm{C}$ \\
\hline AaH5 & $\mathrm{C}$ & G & $\mathrm{T}$ & $\mathrm{T}$ & $\mathrm{T}$ & $\mathrm{C}$ & $\mathrm{C}$ & $\mathrm{C}$ & $\mathrm{C}$ & G & $\mathrm{C}$ & $\mathrm{T}$ & A & A & $\mathrm{C}$ \\
\hline
\end{tabular}

a Consensus sequence of variable nucleotides of each haplotype for the RPB2 locus. Sequences are presented for the 15 unique haplotypes, and number indicates the base position of each variable site. $\mathrm{Y}=\mathrm{C} / \mathrm{T}$ and $\mathrm{R}=\mathrm{A} / \mathrm{G}$.

${ }^{\mathrm{b}}$ A. alternata isolates collected from mainly heirloom tomato were from Henderson, Pender, Sampson, and Stokes counties. 
in other countries. Of the GPDH sequences of the 15 isolates of $A$. alternata from potato in WI of the study of Ding et al. (2019) that we compared, three isolates (Aa3, Aa52, and Aa70 sequences) appeared to be identical to sequences of our five isolates (T9, T16, T36, T71, and T77) of A. alternata from tomato in NC. Based on the mutations, six haplotypes of $A$. solani were inferred for the GPDH locus in the previous study (Lourenço et al. 2009). Among these haplotypes, H2, $\mathrm{H} 3, \mathrm{H} 4$, and $\mathrm{H} 5$ were detected in tomato isolates while haplotypes $\mathrm{H} 1$ and $\mathrm{H} 6$ were found in potato isolates. Based on the frequency from where they originated, haplotype AsAlH4 described here appeared to represent the most important $G P D H$ haplotype within sequences of A. solani isolates from WI and global isolates including Australia, Algeria, Brazil, China, New Zealand, and Russia (Table 1; Fig. 5). The most common haplotype AsAlH2/H3 was found within $A$. linariae from tomato in the current study and was also exclusively present in Algeria, Belgium, China, Demark, Iran, Netherland, Pakistan, Russia, and several other states (e.g., IN, PA, and AZ) of the United States. (Table 1). The results of this study suggest that two haplotypes (AsAlH2/H3 and AsAlH4) could be widely distributed clones in tomato- and potato-growing regions.

Comparison of the $R P B 2$ and $G P D H$ locus-based haplotypes of Alternaria spp. with publicly available Alternaria whole-genome sequences. For both genes, the haplotypes identified in the current study using our approach were compared with publicly available A. alternata and $A$. solani wholegenome sequences. For comparing the RPB2 locus sequences, we identified six haplotypes of the A. alternata and these haplotype sequences had little or no (0 to 8) nucleotide differences between them and their respective isolates (Supplementary Table S5). Importantly, A. alternata haplotype AaH3 identified from the RPB2 gene sequence corresponded perfectly with the reference genome sequence of A. alternata isolate SRC1lrK2f (Supplementary Table $\mathrm{S} 5)$. For the $R P B 2$ locus, $A$. solani representative isolate $\mathrm{P} 2$ sampled from a potato field in WI was identical to the genome sequence of $A$. solani isolate BMP 0185 from Arkansas of the United States. However, there were three nucleotide differences between $A$. solani isolate $\mathrm{P} 2$ and another genome sequence of $A$. solani isolate $\mathrm{HWC}$
168 from China (Supplementary Table S5). Our results show 47 to 50 nucleotide differences between $A$. alternata isolate SRC1lrK2f versus $A$. solani and $A$. linariae, and between $A$. solani isolate BMP 0185 versus $A$. alternata haplotypes.

For the GPDH locus, maximum nucleotide differences resulted in haplotypes of A. alternata when compared with the reference genome of $A$. solani isolate BMP 0185 and isolate HWC 168 or when $A$. solani and $A$. linariae haplotypes were compared with the reference genome of A. alternata isolate SRC1lrK2f (Supplementary Table S6). However, in each of the haplotypes corresponding to $A$. solani and $A$. linariae, there were one to two nucleotide differences. With the GPDH locus-based sequence dataset, A. solani and A. linariae haplotype $\mathrm{P} 1-\mathrm{AsAlH} 4$ was identical with the genome of $A$. solani isolate BMP 0185 and isolate HWC 168 (Supplementary Table S6). Similarly, A. alternata haplotype $\mathrm{T}-5 \mathrm{AaH} 1$ corresponded perfectly with the reference genome of A. alternata isolate SRC1lrK2f.

Sequence data availability. The DNA sequences reported in this study have been deposited in GenBank under the accession numbers MK928512 to MK928663 (ITS), MK928664 to MK928815 (GPDH), and MK928816 to MK928967 (RPB2). Sequences of publicly available Alternaria whole-genome sequences of the three isolates used in this are available from GenBank (https://www.ncbi.nlm.nih.gov/genbank/).

\section{DISCUSSION}

One of the primary objectives of the current study was to use the gene genealogical approach to improve our understanding of the genetic diversity of economically important members of the Alternaria spp. Toward this end, we analyzed 152 isolates of Alternaria spp. sampled from major tomato and potato growing areas in NC and WI. We also included DNA sequence data per isolate used in previous studies (Ding et al. 2019; Lourenço et al. 2009; Woudenberg et al. 2014). As a result, phylogenetic analysis of a single-gene data set was informative to provide the haplotype diversity and evolutionary relationships between species of

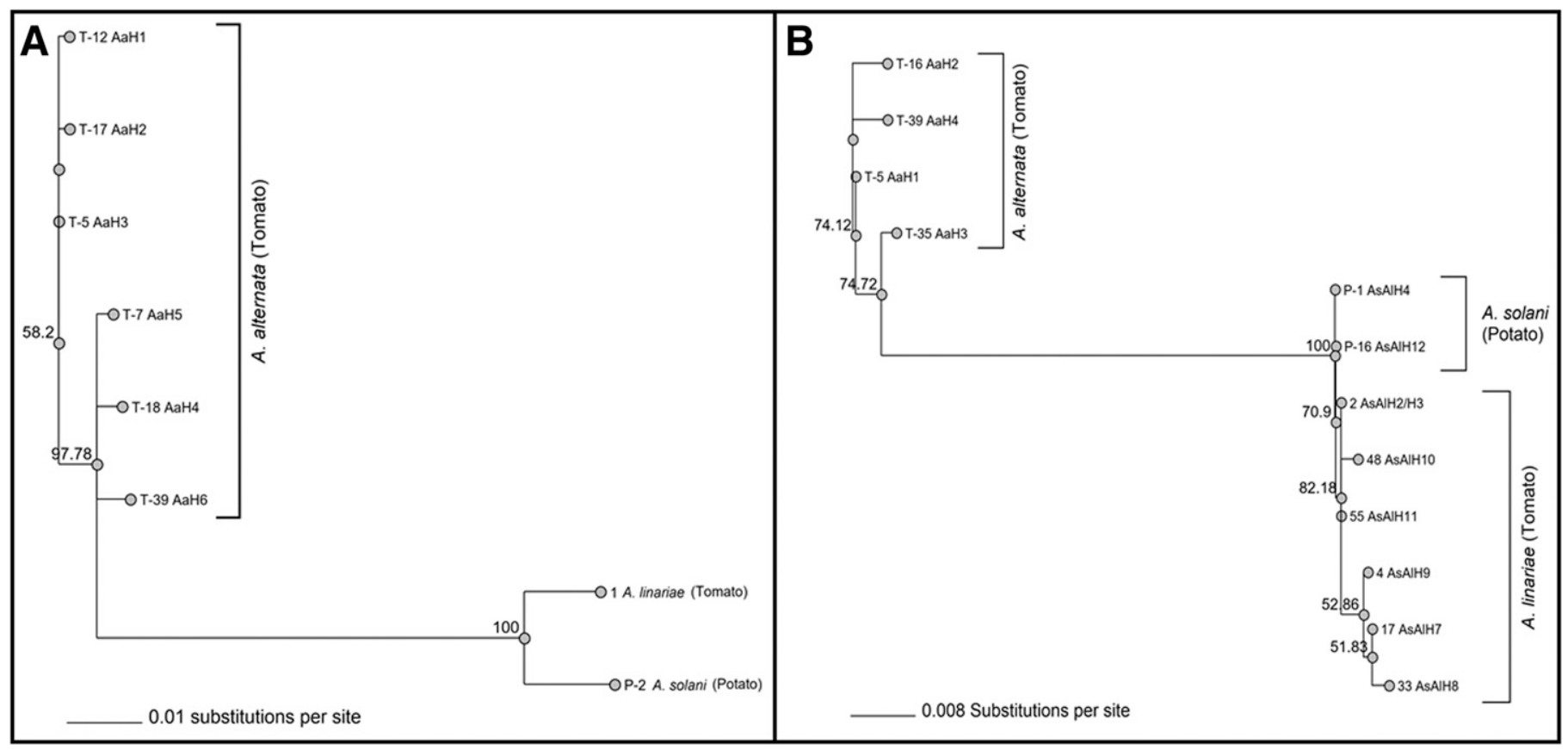

Fig. 2. Phylogenetic relationships of Alternaria alternata (Aa), A. solani (As), and A. linariae (Al) of haplotypes based the sequences of the A, RNA polymerase second largest subunit $(R P B 2)$ and $\mathbf{B}$, glyceraldehyde-3-phosphate dehydrogenase $(G P D H)$. Each number indicates a representative isolate from each haplotype, and letter before isolate number refers to host: $\mathrm{T}=$ tomato and $\mathrm{P}=$ potato from which isolate was collected. All rooted maximum-likelihood trees are drawn to scale with branch lengths proportional to the substitutions per site. Bootstrap support was calculated from 1,000 replicates and values $>50 \%$ are indicated above the branches. 
Alternaria spp. As noted in published phylogenetic studies (Ding et al. 2019; Lourenço et al. 2009; Woudenberg et al. 2015), our results also indicate that nucleotide diversity was lower for the ITS sequences than the $R P B 2$ and $G P D H$ sequences. Although the $R P B 2$ sequences were too conserved and did not distinguish among individuals within A. linariae or within A. solani, nucleotide substitution sites or SNPs were useful to allow delineation at the species level. The GPDH sequences outperformed the other two genes in providing superior resolution for haplotype placement and phylogenetic inference. For A. linariae or A. solani, sequences of haplotypes AsAlH1 to AsAlH6 were identical to previously reported haplotypes from Brazil (Lourenço et al. 2009). The remaining AsAlH7 to AsAlH12 were unique and new haplotypes. Our results suggest that $A$. linariae or $A$. solani contain new and previously reported haplotypes that are capable of causing disease epidemics in tomato- and potato-producing areas in NC and WI.

Low level of genetic diversity was found for Alternaria spp. in this study. Based on the ITS locus, Lourenço et al. (2009) also reported a low level of diversity for isolates of $A$. solani collected from tomato and potato in Brazil. Similarly, ITS locus was less informative and resulted in poor resolution in Fusarium spp. (O'Donnell et al. 2013; Ramdial et al. 2017). In contrast, the GPDH gene sequences were useful and informative to compare the genetic diversity and genetic relationships of Alternaria spp. in previous studies (Ding et al. 2019; Lourenço et al. 2009). In the case of $A$. linariae or A. solani, 13 haplotypes (including unique haplotypes) were identified, and six of them were identical to previously reported haplotypes (Lourenço et al. 2009). The remaining haplotypes were new. Our findings based on the consensus sequence across the GPDH locus suggest that the two most frequently diverse haplotypes, AsAlH2/AsAlH3 and $\mathrm{AsAlH} 4$, were associated with $A$. linariae and $A$. solani in the United States. Interestingly, all global isolates of $A$. linariae and $A$. solani included in this study share these haplotypes. Our findings support previous results showing that the majority of gene diversity may be distributed within individuals and populations are not geographically differentiated (Linde et al. 2002; McDonald et al. 1999). We found seven new haplotypes (AsAlH7 to AsAlH13) that were not present in previously reported haplotypes of A. solani (Lourenço et al. 2009). Among these haplotypes, AsAlH2/AsAlH3 and AsAlH4 have been mainly detected in A. linariae isolates from tomato in $\mathrm{NC}$ and in $A$. solani isolates from potato in WI, respectively, but formed a single clade in the neighbor-joining trees. These two haplotypes also displayed closer proximity to the clusters that contain haplotypes AsAlH7, AsAlH8, AsAlH9, AsAlH10, and AsAlH11 of A. linariae and one haplotype AsAlH12 of $A$. solani. Although population differentiation according to the host of origin in this study was not possible due

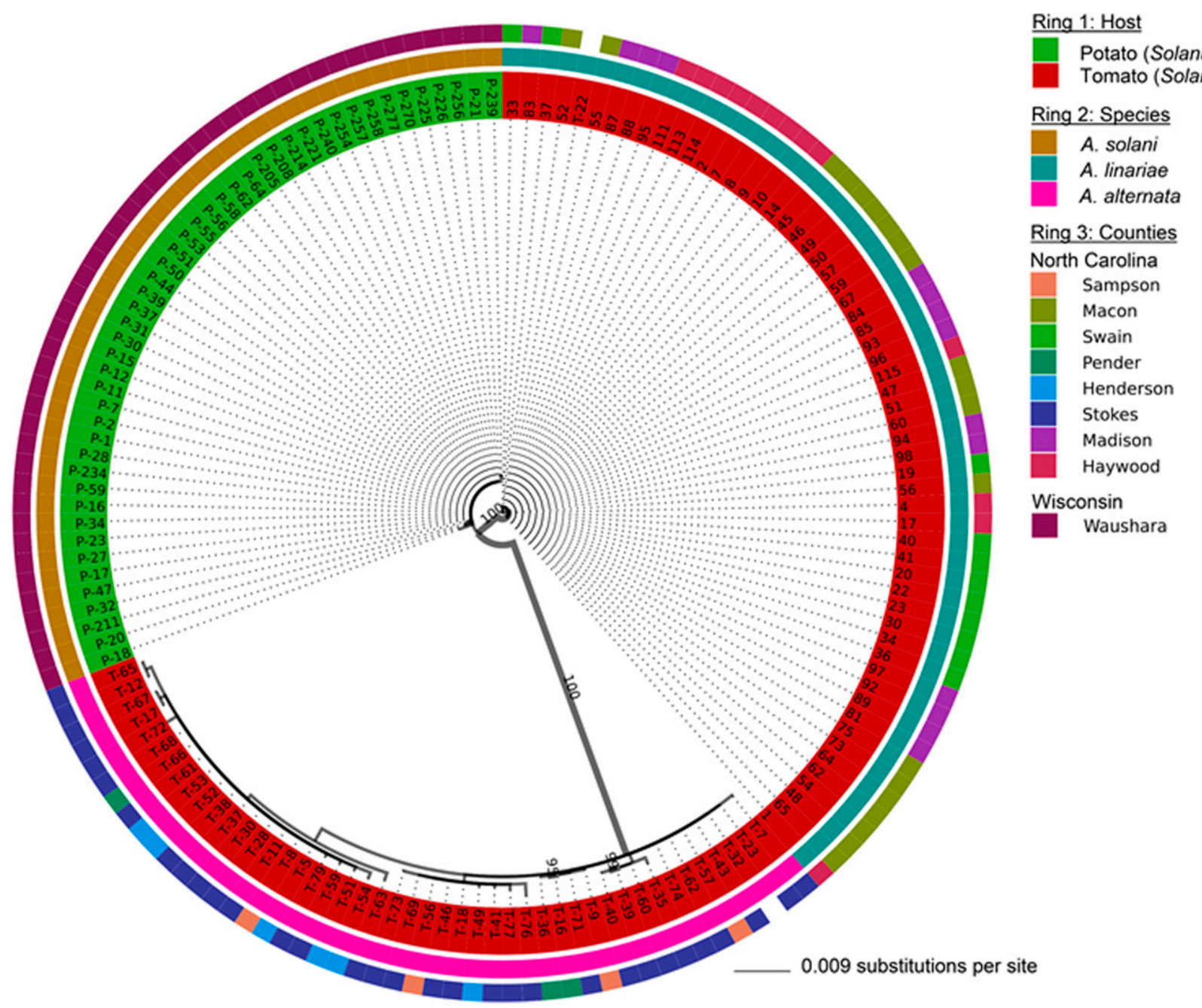

Fig. 3. The phylogenetic tree derived from a concatenated sequence made up of glyceraldehyde-3-phosphate dehydrogenase $(G P D H)$ and RNA polymerase second largest subunit (RPB2), and the rDNA internal transcribed spacer $(I T S)$ region of the 152 isolates of Alternaria alternata $(N=46)$, A. linariae $(N=59)$, and A. solani $(N=47)$ isolates from North Carolina and Wisconsin. Innermost ring: host plant from which isolates were collected and each isolate designation is connected with principal component value. Letter before isolate number refers to host: $\mathrm{T}=$ tomato and $\mathrm{P}=$ potato from which collected; ring 2: fungal species $A$. alternata, A. linariae, and A. solani; and ring 3: state or county from which the isolate was sampled. Bootstrap values $>50$ are labeled along branches. 
to limited sample size and no overlap between tomato and potato, the haplotype association with host species has been demonstrated in the previous study (Lourenço et al. 2009). For example, the $G P D H$ locus-based haplotypes $(\mathrm{H} 1, \mathrm{H} 2, \mathrm{H} 4$, and $\mathrm{H} 5)$ were mainly of tomato isolates, whereas two haplotypes (H6 and H7) were commonly detected in potato isolates from Brazil (Lourenço et al. 2009). Future research will need to collect additional samples from different hosts, geographic locations, and years, and a more detailed assessment involving multigene sequence analysis may provide insight into the genetic diversity of Alternaria spp. across the United States.

Based on combined sequences analysis of four genes (Alt al, $G P D H, I T S$, and translation elongation factor), Ding et al. (2019) reported five genotypes of $A$. alternata from potato sampled in WI. In our study, we also included the 15 isolate sequences of $A$. alternata from potato from the previous study (Ding et al. 2019) for comparisons. Of the 15 isolate sequences analyzed, 12 isolates belonged to genotype I in the previous study and were haplotype $\mathrm{AaH} 1$ in this study. Similarly, one isolate was genotype III and two isolates were genotype V. Although we found the $G P D H$ gene sequence similarities between the isolates of A. alternata from potato sampled in WI and the isolates of A. alternata from tomato sampled in NC, the haplotype nomenclature in the previous study was based on multigene analysis (Ding et al. 2019). However, in our analysis, it was based on single-copy GPDH gene sequences. Haplotype networks of $A$. alternata from tomato are considered to be a conservative exploration of understanding the phylogenetic hypothesis that described the relationships among closely related species such as those of $A$. alternata from potato between the different geographic origin (NC versus WI) and isolates infecting different host plant of origin (tomato versus potato).
We analyzed the genetic variability of Alternaria spp. using two diversity estimates (S and $\pi$ ) (Nei 1973) and assessed simple models of Watterson's $\Theta_{\mathrm{w}}$ (Watterson 1975) and four neutrality tests: D, FLD, FLF, and Fu's F (Carbone et al. 2007; Fu 1997; Fu and Li 1993; Tajima 1989). Data indicate greater $\pi$ and Watterson's $\Theta_{\mathrm{w}}$ estimates in A. alternata than estimates in A. linariae and A. solani isolates. In general, a higher degree of nucleotide diversity is expected in an ancestral population (Nei 1973). Comparatively, S values for all three genes $(G P D H=9, I T S=2$, and $R P B 2=18)$ were higher in A. alternata than A. linariae and A. solani and can explain the differences in nucleotide diversity in these populations. Four neutrality test estimates varied with Alternaria spp. and the nuclear genes analyzed, and most values were not significant. All negative values for the three genes indicated an excess of recent mutation and population expansion in Alternaria spp. The mutation is one of the principal evolutionary mechanisms, which causes a heritable change in the nucleotide sequence in several fungi (Hartl and Clark 2007). We hypothesize that new haplotypes AsAlH7 to AsAlH13 have emerged independently in each population. Our data indicate Tajima's D value was positive, but Fu's $F$ was nonsignificant for the $G P D H$ gene in A. linariae. This result is likely due to balancing selection where the polymorphic alleles are in a position to diversify by additional mutations (Tajima 1989). In this study, A. alternata and $A$. linariae were sampled from tomatoes from limited geographic areas in NC between 2012 and 2014 while A. solani samples were collected from a potato from a single location in WI during the 2008 season. Thus, we were unable to compare haplotypes over time and space or determine whether some historical events had favorable or unfavorable effects on estimating the number of population genomic parameters for the respective pathogen populations.

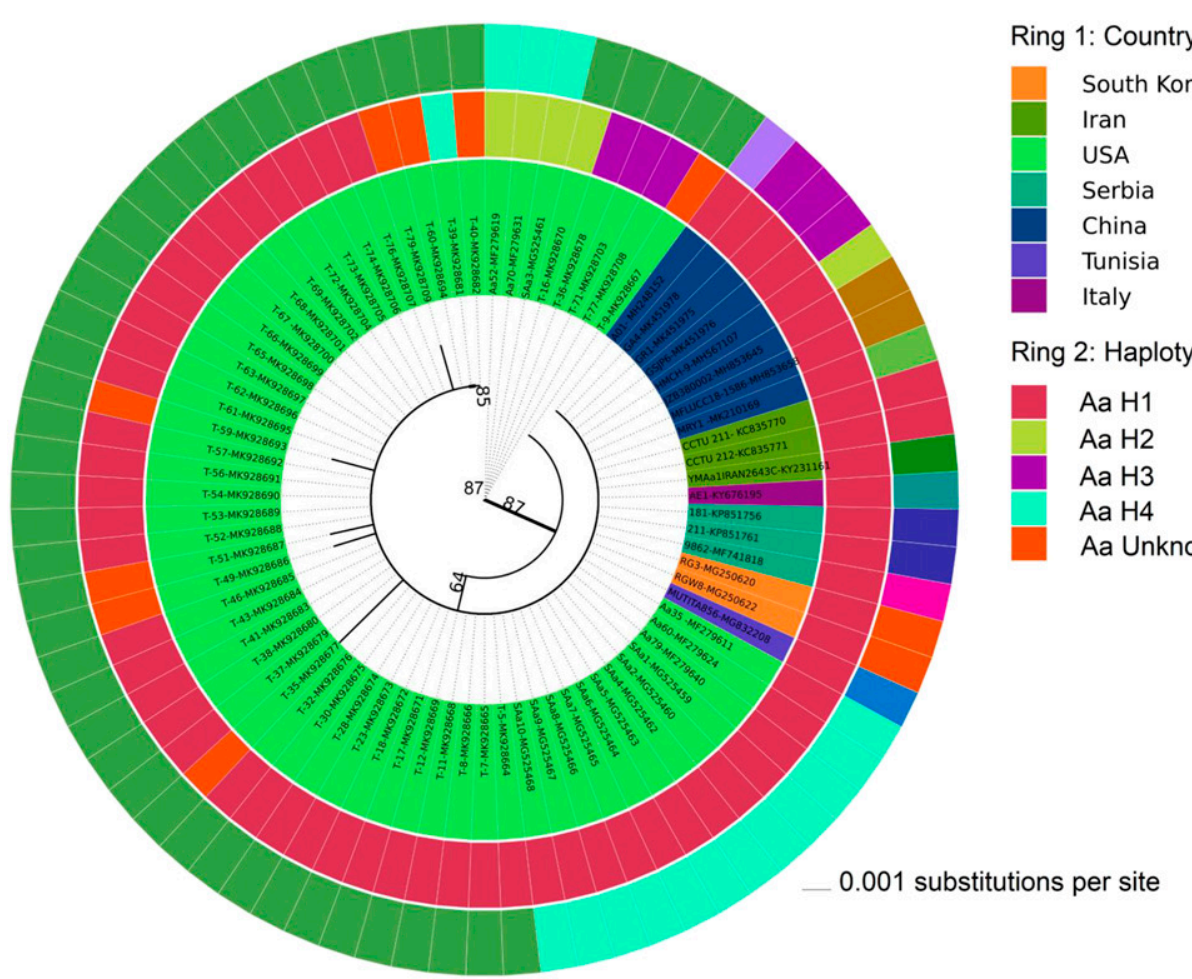

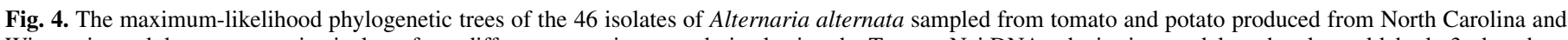

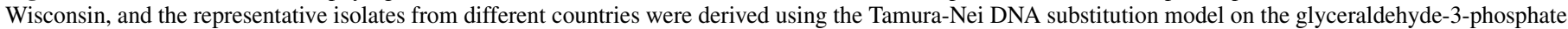



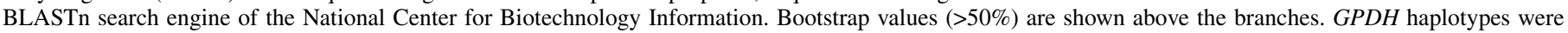

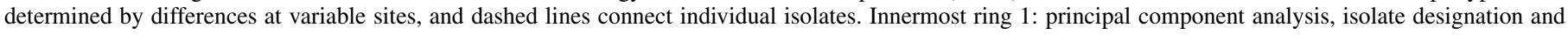

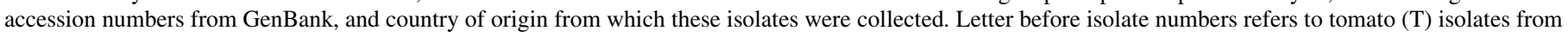

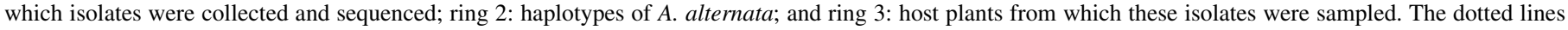
within the ring are cosmetic, and solid lines refer to high nucleotide polymorphisms. 
Morphological characterization of Alternaria large-spored species associated with EB of tomato and potato appeared to be insufficient to distinguish between $A$. solani and $A$. linariae (Woudenberg et al. 2014). Importantly, large-spored A. linariae has been isolated from Solanaceae vegetables with symptoms resembling that of EB at the early stages of infection (Ayad et al. 2017). Interestingly, $A$. linariae was not only specific to tomato but it has also been isolated from potato (Ayad et al. 2017; Bessadat et al. 2016; Rodrigues et al. 2010; Simmons 2000). Since A. solani and $A$. linariae are the most common species and widely distributed in tomato- and potato-producing regions, molecular markers are necessary to identify and differentiate these species. The $R P B 2$ gene encodes a protein with a modest rate of evolutionary change and its polypeptide sequence has been used for phylogenetic studies in green plants (Denton et al. 1998) and ascomycetes, including lichen-forming taxa (Liu and Hall 2004). In the current study, comparative genealogy analyses indicate that gene variations exist in these closely related Alternaria isolates, suggesting that these three Alternaria spp. might have diverged in the genome evolution. In the previous studies, both $G P D H$ and $R P B 2$ genes have been used to compare sequence variation in agriculturally important Fusarium species complex (O'Donnell et al. 2000, 2013) and several Alternaria spp. (Woudenberg et al. 2015; 2014). In particular, we also found that the RPB2 locus sequences provided the most conclusive and specific evidence to delineate two closely related species:
A. linariae and A. solani. We reasoned that both A. linariae and A. solani have identical asexual conidia morphology (Woudenberg et al. 2014) and can cause EB disease in tomato and potato (Ayad et al. 2017; Bessadat et al. 2016). Our result suggests that the development of molecular markers from the $R P B 2$ genomic region can be useful to differentiate $A$. linariae and $A$. solani.

All tomatoes grown in NC are for fresh market. Most of the tomato industries use conventional management practices and utilize the plasticulture system that includes the use of fumigants and conventional fungicides. However, there is a trend of growing organic tomatoes in NC. Tomato cultivars (hybrids, determinate, semideterminate, indeterminate, and heirloom) are diverse, with different combinations of fruit size, growth habit, and disease resistance (https://plantpathology.ces.ncsu.edu/pp-vegetables/ppvegetables-tomatoes/). The isolates of $A$. solani and $A$. linariae were collected in the early season, while isolates of A. alternata were collected from tomato later of the season. EB epidemics on tomato caused by $A$. linariae in western NC are recurrent and could be due to planting susceptible tomato cultivars or hybrids, change in virulence of the pathogen, conducive weather parameters, and climate changes (Anderson et al. 2004; Stukenbrock and Bataillon 2012; Stukenbrock and McDonald 2008; Sumabat et al. 2018). In this study, A. solani isolates were collected from diverse potato breeding lines and sampled from only one location in WI. We found that the majority $(>91 \%)$ of the isolates exhibited haplotype

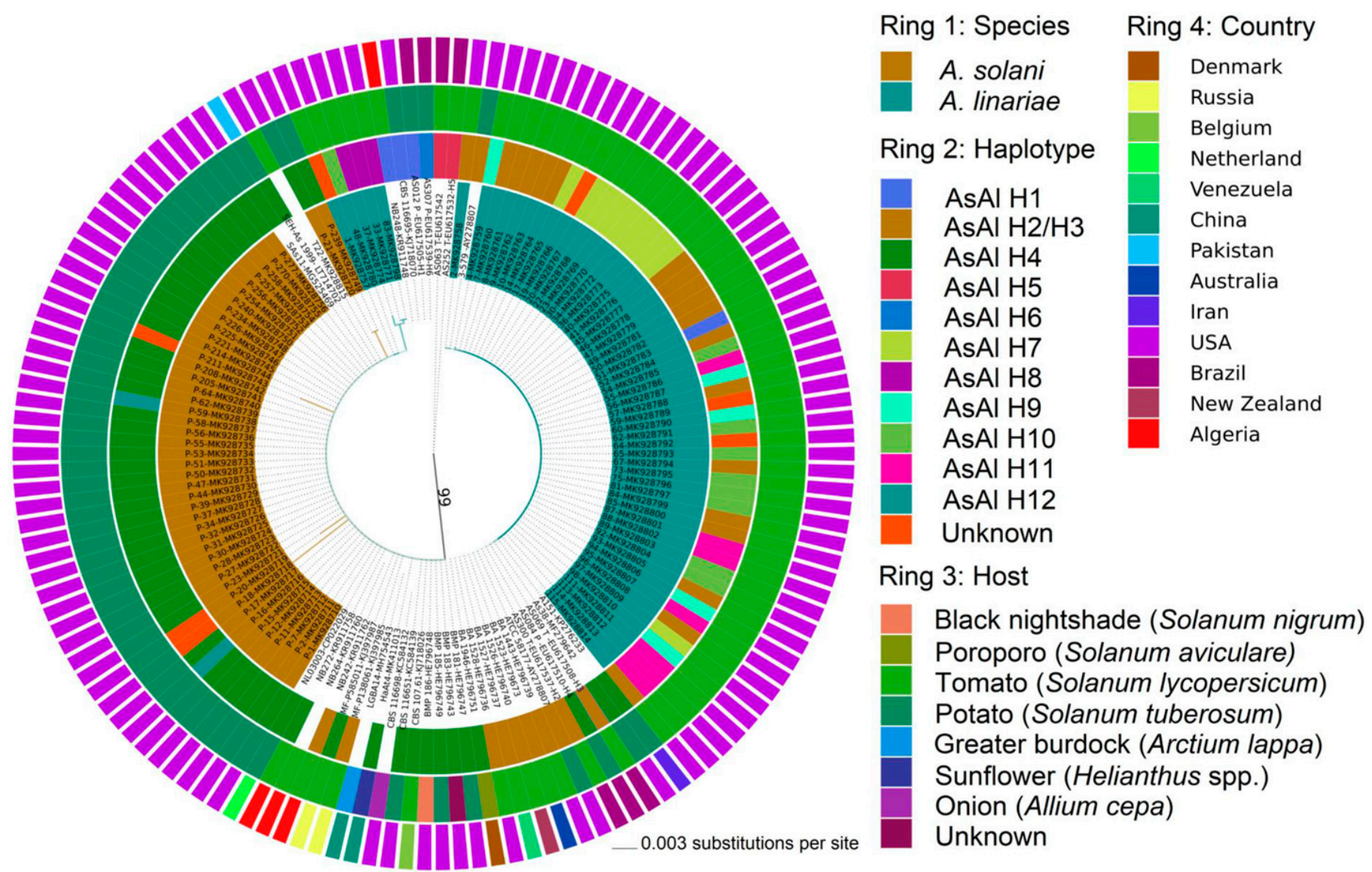

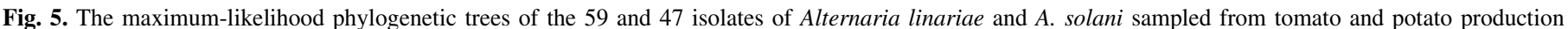

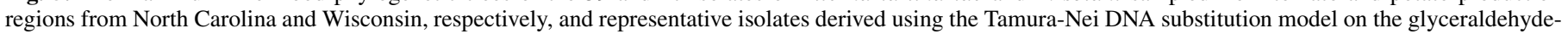

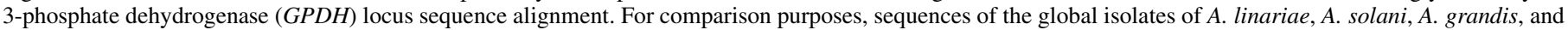

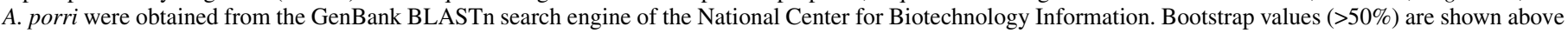

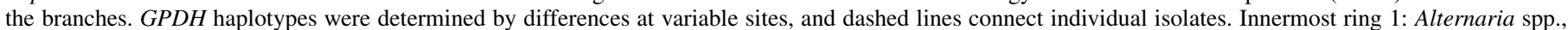

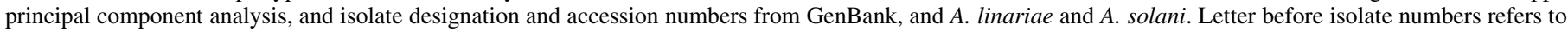

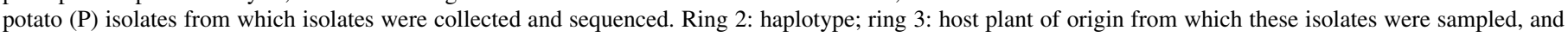

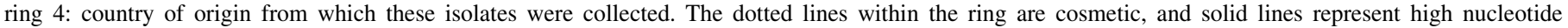
polymorphisms. 
AsAlH4. In the previous study, Ding et al. (2019) analyzed 33 isolates of $A$. solani sampled from Grand Marsh, Hancock, and Plover, which were different sampling sites than in our study. Based on multigene phylogeny, they also found only one genotype of $A$. solani in different potato fields in WI. It appeared that $A$. solani isolates with identical (GPDH, ITS, and RPB2) marker sequences were well established in these environments and can cause disease epidemics in potato in WI.

In conclusion, we used DNA sequencing at multiple loci and genealogical approaches to provide new insights into the population genetic structure of Alternaria spp. This study revealed the presence of previously reported haplotypes and new haplotypes in tomatoand potato-producing areas in NC and WI. Both A. linariae and $A$. solani can cause similar lesions on leaves and have been isolated from single symptomatic leaf tissue of tomato and potato (Ayad et al. 2017; Bessadat et al. 2016; Simmons 2007). SNP-based diagnostic molecular markers can be developed from sequences of the $R P B 2$ gene and used to differentiate these two species.

\section{ACKNOWLEDGMENTS}

We thank Inga Meadows for helping with isolate collection; and Audrey Djunaedi, Stella Chang, and Virginie Rumsch for assisting in the laboratory.

\section{LITERATURE CITED}

Adhikari, P., Oh, Y., and Panthee, D. R. 2017. Current status of early blight resistance in tomato. An update. Int J. Mol. Sci. 18:E2019.

Anderson, P. K., Cunningham, A. A., Patel, N. G., Morales, F. J., Epstein, P. R., and Daszak, P. 2004. Emerging infectious diseases of plants: Pathogen pollution, climate change and agrotechnology drivers. Trends Ecol. Evol. 19:535-544.

Ayad, D., Aribi, D., Hamon, B., Kedad, A., Simoeau, P., and Bouznad, Z. 2017. New data on early blight of potato and tomato caused by a complex of large-spored Alternaria species in Algeria. Pages 167-180 in: Sixteenth Euroblight Workshop, Special Report No. 18, Aarhus, Denmark.

Aylor, D. L., Price, E. W., and Carbone, I. 2006. SNAP: Combine and map modules for multilocus population genetic analysis. Bioinformatics 22: 1399-1401.

Berbee, M. L., Pirseyedi, M., and Hubbard, S. 1999. Cochliobolus phylogenetics and the origin of known, highly virulent pathogens, inferred from ITS and glyceraldehyde-3-phosphate dehydrogenase gene sequences. Mycologia 91:964-977.

Bessadat, N., Berruyer, R., Hamon, B., Bataille-Simoneau, N., Benichou, S., Kihal, M., Henni, D. E., and Simoneau, P. 2016. Alternaria species associated with early blight epidemics on tomato and other Solanaceae crops in northwestern Algeria. Eur. J. Plant Pathol. 148:181-197.

Brewer, M. T., and Milgroom, M. G. 2010. Phylogeography and population structure of the grape powdery mildew fungus, Erysiphe necator, from diverse Vitis species. BMC Evol. Biol. 10:268.

Carbone, I., Jakubek, J. L., Ramirez-Prado, J. H., and Horno, B. W. 2007. Recombination, balancing selection, and adaptive evolution in the aflatoxin gene cluster of Aspergillus parasiticus. Mol. Ecol. 16:4401-4417.

Carbone, I., White, J. B., Miadlikowska, J., Arnold, A. E., Miller, M. A., Kauff, F., U'Ren, J. M., May, G., and Lutzoni, F. 2017. T-BAS: Tree-Based Alignment Selector toolkit for phylogenetic-based placement, alignment downloads, and metadata visualization: An example with the Pezizomycotina tree of life. Bioinformatics 33:1160-1168.

Cochran, W. G. 1977. Sampling Techniques. 3rd ed., Wiley \& Sons, New York.

Dang, H. X., Pryor, B., Peever, T., and Lawrence, C. B. 2015. The Alternaria genomes database: A comprehensive resource for a fungal genus comprised of saprophytes, plant pathogens, and allergenic species. BMC Genomics 16: 239.

Denton, A. L., McConaughy, B. L., and Hall, B. D. 1998. Usefulness of RNA polymerase II coding sequences for estimation of green plant phylogeny. Mol. Biol. Evol. 15:1082-1085.

Ding, S., Meinholz, K., Cleveland, K., Jordan, S. A., and Gevens, A. J. 2019. Diversity and virulence of Alternaria spp. causing potato early blight and brown spot in Wisconsin. Phytopathology 109:436-445.

Droby, S., Dinoor, A., Prusky, D., and Barkai-Golan, R. 1984. Pathogenicity of Alternaria alternata on potato in Israel. Phytopathology 74:537-542.

Edgar, R. C. 2004. MUSCLE: Multiple sequence alignment with high accuracy and high throughput. Nucleic Acids Res. 32:1792-1797.

Fu, Y. 1997. Statistical tests of neutrality of mutations against population growth, hitchhiking and background selection. Genetics 147:915-925.
$\mathrm{Fu}$, Y., and Li, W. 1993. Statistical tests of neutrality of mutations. Genetics 133:693-709.

Gannibal, P. B., Orina, A. S., and Mironenko, N. V. 2014. Differentiation of the closely related species, Alternaria solani and A. tomatophila, by molecular and morphological features and aggressiveness. Eur. J. Plant Pathol. 139:609-623.

Grogan, R. G., Kimble, K. A., and Misaghi, I. 1975. A stem canker disease caused by Alternaria alternata f. sp. lycopersici. Phytopathology 65:880-886.

Hartl, D. L., and Clark, A. G. 2007. Principles of Population Genetics. Sinauer Associates, Sunderland, MA.

Jakobsen, I. B., Wilson, S. R., and Easteal, S. 1997. The partition matrix: Exploring variable phylogenetic signals along nucleotide sequence alignments. Mol. Biol. Evol. 14:474-484.

Jones, J. B., Zitter, T. A., Timur, M. T., and Miller, S. A. 2014. Page 176 in: Compendium of Tomato Diseases and Pests, 2nd ed. American Phytopathological Society, St. Paul, MN.

Kimura, M. 1980. A simple method for estimating the evolutionary rate of base substitution through comparative studies of nucleotide sequences. J. Mol. Evol. 16:111-120.

Kuhar, T. P., Ramon Arancibia, R., Rideout, S. L., and Reiter, M. S. 2019. Southeastern U.S. 2019 Vegetable Crop Handbook. AREC-66NP (SPES106NP). Virginia Cooperative Extension, Virginia Tech, and Virginia State University. https://www.pubs.ext.vt.edu/AREC/AREC-66/AREC-66. html

Librado, P., and Rozas, J. 2009. DnaSP v5: A software for comprehensive analysis of DNA polymorphism data. Bioinformatics 25:1451-1452.

Linde, C. C., Zhan, J., and McDonald, B. A. 2002. Population structure of Mycosphaerella graminicola: From lesions to continents. Phytopathology 92:946-955

Liu, Y. J., and Hall, B. D. 2004. Body plan evolution of ascomycetes, as inferred from an RNA polymerase II phylogeny. Proc. Natl. Acad. Sci. USA 101:4507-4512

Lourenço, V., Jr., Moya, A., González-Candelas, F., Carbone, I., Maffia, L. A., and Mizubuti, E. S. G. 2009. Molecular diversity and evolutionary processes of Alternaria solani in Brazil inferred using genealogical and coalescent approaches. Phytopathology 99:765-774.

McDonald, B. A., Zhan, J., Yarden, O., Hogan, K., Garton, J., and Pettway, R. E. 1999. The population genetics of Mycosphaerella graminicola and Phaeosphaeria nodorum. Pages 44-69 in: Septoria on Cereals: A Study of Pathosystems. H. M. Anderson, ed. CABI, Wallingford, U.K.

Nei, M. 1973. Analysis of gene diversity in subdivided population. Proc. Natl. Acad. Sci. USA 70:3321-3323.

O’Donnell, K., Kistler, H. C., Tacke, B. K., and Casper, H. H. 2000. Gene genealogies reveal global phylogeographic structure and reproductive isolation among lineages of Fusarium graminearum, the fungus causing wheat scab. Proc. Natl. Acad. Sci. USA 97:7905-7910.

O’Donnell, K., Rooney, A. P., Proctor, R. H., Brown, D. W., McCormick, S. P., Ward, T. J., Frandsen, R. J., Lysøe, E., Rehner, S. A., Aoki, T., Robert, V. A., Crous, P. W., Groenewald, J. Z., Kang, S., and Geiser, D. M. 2013. Phylogenetic analyses of RPB1 and RPB2 support a middle Cretaceous origin for a clade comprising all agriculturally and medically important fusaria. Fungal Genet. Biol. 52:20-31.

Peever, T. L., Ibañez, A., Akimitsu, K., and Timmer, L. W. 2002. Worldwide phylogeography of the citrus brown spot pathogen, Alternaria alternata. Phytopathology 92:794-802.

Price, E. W., and Carbone, I. 2005. SNAP: Workbench management tool for evolutionary population genetic analysis. Bioinformatics 21:402-404.

Pryor, B., and Gilbertson, R. 2000. Molecular phylogenetic relationships amongst Alternaria species and related fungi based upon analysis of nuclear ITS and mt SSU rDNA sequences. Mycol. Res. 104:1312-1321.

Ramdial, H., Latchoo, R. K., Hosein, F. N., and Rampersad, S. N. 2017. Phylogeny and haplotype analysis of fungi within the Fusarium incarnatum-equiseti species complex. Phytopathology 107:109-120.

Rebbeck, T. R., Ambrosone, C. B., Bell, D. A., Chanock, S. J., Hayes, R. B., Kadlubar, F. F., and Thomas, D. C. 2004. SNPs, haplotypes, and cancer: Applications in molecular epidemiology. Cancer Epidemiol. Biomarkers Prev. 13.

Rodrigues, T. T. M. S., Berbee, M. L., Simmons, E. G., Cardoso, C. R., Reis, A., Maffia, L. A., and Mizubuti, E. S. G. 2010. First report of Alternaria tomatophila and A. grandis causing early blight on tomato and potato in Brazil. New Dis. Rep. 22:28.

Rotem, J. 1994. Page 48 in: The Genus Alternaria Biology, Epidemiology, and Pathogenicity, 1st ed. American Phytopathological Society, St. Paul, MN.

Rozas, J., Ferrer-Mata, A., Sánchez-DelBarrio, J. C., Guirao-Rico, S., Librado, P., Ramos-Onsins, S. E., and Sánchez-Gracia, A. 2017. DnaSP 6. DNA Seq. Polymorph. Anal. Large Datasets. Mol. Biol. Evol. 34:3299-3302.

Simmons, E. G. 2000. Alternaria themes and variations (244-286) species on Solanaceae. Mycotaxon 75:1-115.

Simmons, E. G. 2007. Alternaria: An Identification Manual. CBS Fungal Biodiversity Centre, Utrecht, Netherlands. 
Stukenbrock, E. H., and Bataillon, T. 2012. A population genomics perspective on the emergence and adaptation of new plant pathogens in agro-ecosystems. PLoS Pathog 8:e1002893.

Stukenbrock, E. H., and McDonald, B. A. 2008. The origins of plant pathogens in agro-ecosystems. Annu. Rev. Phytopathol. 46:75-100.

Sumabat, L. G., Kemerait, R. C., Jr., and Brewer, M. T. 2018. Phylogenetic diversity and host specialization of Corynespora cassiicola responsible for emerging target spot disease of cotton and other crops in the southeastern United States. Phytopathology 108:892-901.

Swofford, D. L. 2004. PAUP*: Phylogenetic analysis using parsimony (*and other methods). Version 4b10. Sinauer Associates, Sunderland, MA.

Tajima, F. 1989. Statistical method for testing the neutral mutation hypothesis by DNA polymorphism. Genetics 123:585-595.

Tamura, K., and Nei, M. 1993. Estimation of the number of nucleotide substitutions in the control region of mitochondrial DNA in humans and chimpanzees. Mol. Biol. Evol. 10:512-526.

USDA-NASS. 2018. United States Department of Agriculture (USDA)National Agricultural Statistics Service (NASS). https://www.nass.usda. gov/Publications/Ag_Statistics/2018/index
Watterson, G. A. 1975. On the number of segregating sites in genetical models without recombination. Theor. Popul. Biol. 7:256-276.

Weber, B., and Halterman, D. A. 2012. Analysis of genetic and pathogenic variation of Alternaria solani from a potato production region. Eur. J. Plant Pathol. 134:847-858.

White, T. J., Bruns, T., Lee, S., and Taylor, J. 1990. Amplification and direct sequencing of fungal ribosomal RNA genes for phylogenetics. Pages 315-322 in: PCR Protocols: A Guide to Methods and Applications. M. A. Innis, D. H. Gelfand, J. J. Sninsky, and T. J. White, eds. Academic Press, San Diego, CA.

Woudenberg, J. H., Truter, M., Groenewald, J. Z., and Crous, P. W. 2014. Large spored Alternaria pathogens in section Porri disentangled. Stud. Mycol. 79:1-47.

Woudenberg, J. H. C., Seidl, M. F., Groenewald, J. Z., de Vries, M., Stielow, J. B., Thomma, B. P. H. J., and Crous, P. W. 2015. Alternaria section Alternaria: Species, formae speciales or pathotypes? Stud. Mycol. 82:1-21.

Zaffarano, P. L., McDonald, B. A., and Linde, C. C. 2009. Phylogeographical analyses reveal global migration patterns of the barley scald pathogen Rhynchosporium secalis. Mol. Ecol. 18:279-293. 